\title{
CTGF siRNA ameliorates tubular cell apoptosis and tubulointerstitial fibrosis in obstructed mouse kidneys in a Sirtl-independent manner
}

This article was published in the following Dove Press journal:

Drug Design, Development and Therapy

31 July 2015

Number of times this article has been viewed

\section{Yunzhuo Ren* \\ Chunyang Du* \\ Li Yan \\ Jingying Wei \\ Haijiang Wu \\ Yonghong Shi \\ Huijun Duan}

Department of Pathology, Hebei Medical University, Shijiazhuang, Hebei, People's Republic of China

*These authors contributed equally to this work
Correspondence: Yonghong Shi;

Huijun Duan

Department of Pathology, Hebei Medical

University, Shijiazhuang, Hebei 0500 I7,

People's Republic of China

Tel +8631 II $86261039 ;+8631 I 86266942$

Fax +8631186043026

Email yonghongshi@I63.com;

duanhi999@163.com

\begin{abstract}
Transforming growth factor- $\beta 1$ (TGF- $\beta 1$ ) plays an important role in the pathogenesis and progression of chronic kidney disease. Connective tissue growth factor (CTGF) is a critical fibrogenic mediator of TGF- $\beta 1$. Mammalian sirtuin 1 (Sirt1) is reported to attenuate renal fibrosis by inhibiting the TGF- $\beta 1$ pathway. This study was designed to detect whether the delivery of CTGF siRNA in vivo directly ameliorates renal fibrosis. Furthermore, the relationship with Sirt1 underlying the protective effect of CTGF siRNA on interstitial fibrosis and apoptosis was explored. Here, we report that the expressions of CTGF and TGF- $\beta 1$ were increased while Sirt1 expression and activity were both dramatically decreased in mouse kidneys with unilateral ureteral obstruction. Recombinant human TGF- $\beta 1$ treatment in HK-2 cells increased CTGF levels and remarkably decreased Sirt1 levels and was accompanied by apoptosis and release of fibrosis-related factors. Recombinant human CTGF stimulation also directly induced apoptosis and fibrosis. The CTGF siRNA plasmid ameliorated tubular cell apoptosis and tubulointerstitial fibrosis, but did not affect Sirt1 expression and activity both in vivo and in vitro. Furthermore, overexpression of Sirt1 abolished TGF- $\beta 1$-induced cell apoptosis and fibrosis, while Sirt1 overexpression suppressed CTGF expression via stimulation by TGF- $\beta 1$. This study provides evidence that treatment strategies involving the delivery of siRNA targeting potentially therapeutic transgenes may be efficacious. Our results suggest that the decrease in Sirt1 is associated with the upregulated expression of CTGF in renal fibrosis, and may aid in the design of new therapies for the prevention of renal fibrosis.
\end{abstract}

Keywords: ureteral obstruction, Sirt1, CTGF, fibrosis, apoptosis

\section{Introduction}

Interstitial fibrosis is correlated with the progression of chronic renal diseases and has been proposed as a final common pathway to end-stage renal diseases. ${ }^{1}$ Unilateral ureteral obstruction (UUO) results in a number of pathophysiological and morphological changes in the renal parenchyma, including interstitial fibrosis and inflammation and apoptotic changes in tubular and interstitial cells. ${ }^{2}$ Apoptosis is a process of normal cell death that maintains tissue homeostasis, but excessive apoptosis or its dysregulation can lead to various pathological fibrosis processes, such as those seen in patients with idiopathic pulmonary fibrosis ${ }^{3}$ and several liver fibrosis diseases. ${ }^{4}$ Renal tubular cells comprise the bulk of the renal cortex, and apoptosis of the tubular cells combined with epithelial-mesenchymal transition (EMT) is the major cause of tubular atrophy. ${ }^{5}$ Moreover, apoptosis has been found in renal tubular cells from patients with diabetic nephropathy. ${ }^{6} \mathrm{~A}$ variety of cytokines are known to affect the processes of interstitial fibrosis (ie, PAI-1 and TIMP-1). $\alpha$-SMA is a molecular hallmark of fibroblast activation during the fibroblast-to-myofibroblast 
transition. Therefore, we examined the levels of PAI-1, TIMP-1, and $\alpha$-SMA. An increase in Bax and a concomitant decrease in Bcl-2 are common markers of apoptosis. Following the original study by Gobe and Axelsen, ${ }^{7}$ there have been numerous reports concerning the role of tubular apoptosis in mediating eventual tubular atrophy as a consequence of chronic UUO. ${ }^{8}$ Clinical and experimental studies have identified a key role for connective tissue growth factor (CTGF/CCN2) in the development of interstitial fibrosis. CTGF, a member of the CCN (Cyr61, CTGF, Nov) family of secretory proteins, is involved in various cellular functions (ie, adhesion, migration, proliferation, and extracellular matrix production), and plays a critical role in many fibrotic conditions, including kidney fibrosis. ${ }^{9,10} \mathrm{CCN}$ proteins regulate many aspects of cellular functions including apoptosis. It has also been demonstrated that CTGF induces apoptosis in human mesangial cells ${ }^{11}$ and that CTGF siRNA ameliorates retinal cell apoptosis in streptozotocin-induced diabetic rats. ${ }^{12}$

Mammalian sirtuin 1 (Sirt1), a nicotinamide adenine dinucleotide $\left(\mathrm{NAD}^{+}\right)$-dependent protein class III deacetylase, is widely expressed in almost all mammalian organs. Sirt1 is a key modulator of cell proliferation, hormone responses, stress responses, apoptosis, and cell metabolism ${ }^{13,14}$ through the deacetylation of the lysine residues of not only histone proteins but also those of some nuclear proteins, such as $\mathrm{p} 53$, the forkhead family proteins, and c-Myc. A recent study demonstrated that Sirt1 activation ameliorated renal fibrosis by inhibiting the TGF- $\beta 1$ (transforming growth factor- $\beta 1$ )/ Smad3 pathway. ${ }^{15}$ Sirt1 was shown to be capable of interacting with TGF- $\beta 1$ signaling and reducing apoptosis in TGF$\beta 1$-treated mesangial cells. ${ }^{16}$ Moreover, the Sirt1 activator SRT1720 significantly reduced TdT-dUTP nick end labeling (TUNEL)-positive apoptosis and collagen I expression in the medulla of the obstructed kidney after UUO. ${ }^{17}$

In this study, we explored the role of CTGF siRNA in matrix accumulation, EMT, apoptosis, and Sirt1 expression using an in vivo model of progressive kidney fibrosis induced by UUO. We also performed studies in vitro to determine whether Sirt1 was involved in the TGF- $\beta 1$-induced CTGF increase and its profibrotic action.

\section{Materials and methods}

\section{Animal model and experimental design}

Twelve-week-old male CD-1 mice (Charles River Laboratories, Vitalriver, Beijing, People's Republic of China) were housed in the animal facilities of the Hebei Medical University with free access to food and water. The animals were randomly divided into three groups: a sham operation group (Sham), a UUO group (UUO), and a UUO group administered a pBAsi mU6 Neo CTGF siRNA plasmid (Takara Bio Inc., Shiga, Japan) (siRNA) (N=8 per group). UUO surgery was performed under general anesthesia. Complete ureteral obstruction was performed by doubleligating the left ureter using 4.0 silk after a midline abdominal incision. Sham-operated mice had their ureters exposed and manipulated, but not ligated. Plasmids were administered into mice by electroporation. The kidney received $100 \mu \mathrm{L}$ containing $50 \mu \mathrm{g}$ of DNA. The injection was done with one $50 \mu \mathrm{L}$ delivery to the lower portion of the kidney, and the other $50 \mu \mathrm{L}$ to the upper portion. Both injections were given in the medulla. The control vector contained sequences necessary for transcription, but no exogenous DNA was added to the vector. Tweezer electrodes (BTXT weezertrodes Model \#522, Harvard Apparatus, Holliston, MA, USA) connected to an electro-stimulator (Electro Cell Manipulator ${ }^{\mathrm{TM}}, \mathrm{ECM}^{\circledR}$ 830, BTX, a division of Genentronics, Harvard Apparatus) were placed on opposite sides of the kidney, and 20 pulses were administered at $200 \mathrm{~V}$, each lasting 20 milliseconds, at 1,000 Hz. ${ }^{18}$ The animals were sacrificed by exsanguination under general anesthesia, and the kidneys were harvested at 7 days after the UUO or sham operation. All procedures were performed in compliance with the guidelines established by the Ethics Review Committee for Animal Experimentation of Hebei Medical University.

\section{Generation of the pBAsi mU6 Neo CTGF siRNA plasmid}

Three CTGF siRNA plasmids were constructed on the basis of the U6 siRNA expression vector pBAsi mU6 Neo (Takara, Mie, Japan), which includes a mouse U6 promoter and an amp-resistance gene. The following sets of sense and antisense oligonucleotides were annealed and ligated into the vector: sense oligo 1: 5'-GATCCGATACCAATGCACTTGCCTGTAGTG CTCCTGGTTGCAGGCAAGTGCATTGGTATCTTTTTTA -3'; antisense oligo 1: 5'-AGCTTAAAAAAGATACCAATGC ACTTGCCTGCAACCAGGAGCACTACAGGCAAGTGCA TTGGTATCG-3'; sense oligo 2: 5'-GATCCGGACATACAG GGCTAAGTTCTAGTGCTCCTGGTTGGAACTTAGCCC TGTATGTCCTTTTTTA-3'; antisense oligo 2: 5'-AGCTTA AAAAAGGACATACAGGGCTAAGTTCCAACCAGGA GCACTAGAACTTAGCCCTGTATGTCCG-3'; sense oligo 3: 5'-GATCCGCTATGATGCGAGCCAACTGTAGTGCTC CTGGTTGCAGTTGGCTCGCATCATAGCTTTTTTA-3'; and antisense oligo 3: 5'-AGCTTAAAAAAGCTATGATGC GAGCCAACTGCAACCAGGAGCACTACAGTTGGCTC GCATCATAGCG-3'. 
To test the efficiency of the three pBAsi mU6 Neo CTGF siRNA plasmids, mouse mesangial cells cultured under highglucose conditions were transfected with the plasmids, and the plasmids were delivered by electroporation into UUO mice in vivo. CTGF expression was evaluated by Western blotting and immunohistochemistry. The most effective plasmid (oligo 1) was used for the study. One group of UUO mice received an injection of CTGF siRNA plasmid DNA at $1 \mathrm{mg} / \mathrm{kg}$ body wt at day 1 before the operation, and every 5 days thereafter, while another group received an injection of pBAsi mU6 Neo control plasmid in an identical manner.

\section{Histological analysis}

Kidneys were fixed in 4\% paraformaldehyde overnight and embedded in paraffin. Sections $(2 \mu \mathrm{m})$ were stained with Masson's trichrome for light microscopic observation. The fibrotic area was measured quantitatively using HPIAS2000 image analysis software (Champion Image Company, Wuhan, People's Republic of China). Thirty randomly selected fields were examined by two investigators without knowledge of the treatment protocol. The results were expressed as the percent area of interstitial fibrosis. ${ }^{19}$

\section{Immunohistochemistry}

Kidney sections $(4 \mu \mathrm{m})$ were deparaffinized with xylene and rehydrated in graded ethanol. Endogenous horseradish peroxidase (HRP) activity was blocked with $3 \% \mathrm{H}_{2} \mathrm{O}_{2}$ in methanol for 30 minutes. Antigen retrieval was performed by microwave treatment in $10 \mathrm{mM}$ citrate buffer for 15 minutes. The sections were incubated with $\alpha$-SMA, TIMP-1, and PAI-1 (Santa Cruz Biotechnology, Santa Cruz, CA, USA) antibodies overnight at $4^{\circ} \mathrm{C}$. Then, the sections were washed and incubated with biotinylated secondary antibody and HRP-conjugated streptavidin. Labeling was visualized with 3,3-diaminobenzidine (DAB; Sigma, St Louis, MO, USA) to produce a brown color, and the sections were counterstained with hematoxylin.

\section{In vivo detection of apoptotic cells}

Apoptotic cells in kidneys were identified using the Dead End TM Colorimetric TUNEL System (Promega, Madison, WI, USA). Briefly, $4 \mu \mathrm{m}$ paraffin sections were treated with freshly diluted $20 \mu \mathrm{g} / \mathrm{mL}$ proteinase $\mathrm{K}$ for 15 minutes at room temperature. After treatment with equilibration buffer for 10 minutes, the recombinant terminal deoxynucleotidyl transferase reaction mix was added for 60 minutes at $37^{\circ} \mathrm{C}$. Endogenous peroxidase activity was blocked by incubating the sections in $0.3 \% \mathrm{H}_{2} \mathrm{O}_{2}$ in phosphate-buffered saline (PBS) for 5 minutes. Streptavidin HRP solution was added to each slide and incubated for 30 minutes at room temperature. Then, the sections were washed, developed in DAB, and counterstained with a light hematoxylin. The numbers of the tubular and interstitial TUNEL-positive apoptotic cells in the entire cortex were scored on the slides.

\section{Cell culture and transient transfection}

HK-2 cells (ATCC, American Type Culture Collection, Manassas, VA, USA) were cultured in Dulbecco's Modified Eagle Medium: Nutrient Mixture F-12 (DMEM-F12) medium supplemented with 5\% fetal bovine serum, $2 \mathrm{mM}$ L-glutamine, $100 \mathrm{U} / \mathrm{mL}$ penicillin, and $100 \mu \mathrm{g} / \mathrm{mL}$ streptomycin in a $95 \%$ air, $5 \% \mathrm{CO}_{2}$ atmosphere. $\mathrm{HK}-2$ cells were divided into the normal group (NG), TGF- $\beta 1$ (5 ng/mL) (Abgent, San Diego, CA, USA) stimulation group, and TGF- $\beta 1$ ( $5 \mathrm{ng} / \mathrm{mL})$ plus CTGF siRNA group. Meantime, to examine the direct effect of CTGF on interstitial fibrosis, HK-2 cells were randomly divided into two groups: the NG group and the CTGF (10 ng/mL) stimulation group. Furthermore, we transfected cells with Sirt1 overexpression plasmid ${ }^{20}$ (addgene.com, plasmid 1791) to observe the effect of Sirt1 overexpression on interstitial fibrosis and CTGF in the presence of rhTGF- $\beta 1$. HK-2 cells were randomly divided into three groups: $\mathrm{NG}$, the TGF- $\beta 1$ ( $5 \mathrm{ng} / \mathrm{mL})$ stimulation group, and the TGF- $\beta 1$ (5 ng/mL) plus Sirt1 overexpression group. Transfections of HK-2 cells with CTGF siRNA plasmid or Sirt1 overexpression plasmid were performed with Lipofectamine 2000 according to the manufacturer's instructions. A negative control plasmid was transfected at the same time.

\section{Immunocytochemistry}

HK-2 cells were grown on chamber slides and fixed with 96\% alcohol after 24 hours under experimental conditions. After washing with PBS $(0.14 \mathrm{M} \mathrm{NaCl}, 0.004 \mathrm{M} \mathrm{KCl}$, and $0.01 \mathrm{M} \mathrm{Na}_{2} \mathrm{HPO} 4 \cdot 12 \mathrm{H}_{2} \mathrm{O}$ ), the cells were incubated with primary mouse monoclonal antibodies against Sirt1 (Abcam, ab110304) overnight at room temperature. Then, the cells were incubated with biotin-conjugated goat antimouse secondary antibody (Dako) and exposed to streptavidin-peroxidase and DAB. Negative controls were obtained by incubating with nonimmune serum instead of the Sirt1 antibody.

\section{In vitro detection of apoptosis}

Apoptosis was assessed by TUNEL, and then the apoptotic cells were counted. Apoptotic cells were defined by chromatin condensation or nuclear fragmentation. Apoptotic cells in different groups were determined using an Annexin V/PI (propidium iodide) apoptosis detection kit according to 
manufacturer's protocol (Multi Sciences Biotech, Hangzhou, People's Republic of China). Briefly, the cell pellet was resuspended in $1 \times$ binding buffer, followed by incubation with $5 \mathrm{~mL}$ of Annexin V (conjugated with fluorescein isothiocyanate) and $10 \mathrm{~mL}$ of PI in the dark for 5 minutes. Then, cell fluorescence was analyzed using a flow cytometer (FCM) (Epics-XLII, Beckman Coulter, Inc, Pasadena, CA, USA). This test discriminates intact cells (Annexin V-/PI-), early apoptotic cells (Annexin V+/PI-), and late apoptotic cells (Annexin V+/PI+). Finally, Hoechst 33258 staining was also used to detect apoptotic cells. Briefly, the cells were washed with PBS, fixed in 10\% formaldehyde solution for 5 minutes at room temperature, and resuspended in $50 \mathrm{~mL}$ of PBS before deposition onto coverslips. The adhered cells were incubated with Hoechst 33258 dye (Invitrogen, Carlsbad, CA, USA) for 20 minutes at room temperature. The coverslips were rinsed with PBS and imaged by fluorescence microscopy (BX3CBH Olympus, Tokyo, Japan). The apoptotic cell counts were expressed as a percentage of the total number of cells emitting fluorescence.

\section{Western blot analysis}

Whole kidneys were homogenized in ice-cold radioimmunoprecipitation assay lysis buffer, then centrifuged at $14,000 \times g$ for 25 minutes at $4^{\circ} \mathrm{C}$ prior to collection of the supernatants. The protein concentration was measured by Bradford's method, and the supernatants were stored at $-80^{\circ} \mathrm{C}$. The cell lysates $(50 \mu \mathrm{g}$ of protein/lane) or whole HK-2 cell extracts ( $40 \mu \mathrm{g}$ of protein/lane) were loaded, separated by sodium dodecyl sulfate-polyacrylamide gel electrophoresis, and transferred to polyvinylidenedifluoride membranes (Millipore, Billerica, MA, USA). The membranes were incubated overnight at $4^{\circ} \mathrm{C}$ with primary antibodies for CTGF (Abcam, Cambridge, UK), TGF- $\beta 1$, collagen type I (Col1), $\alpha$-SMA, TIMP-1, PAI-1, E-cad, or $\beta$-actin (Santa Cruz Biotechnology). Subsequently, the membranes were incubated with goat antirabbit IgG or goat antimouse IgG HRP conjugate, and then immersed in ECL Plus Western Blotting Detection Reagent (Amersham, Piscataway, NJ, USA) and exposed to Hyperfilm ECL (Amersham). The intensity of the bands was measured using Lab Works 4.5 software (UVP, Upland, CA, USA).

\section{Real-time quantitative PCR analysis}

Total RNA and cDNA were prepared from whole kidney samples using the SV Total RNA Isolation System (Promega, Madison, WI, USA) or cultured cells using TRIzol reagent (Invitrogen, Carlsbad, CA, USA) and RT-PCR kits (Promega, Madison, WI, USA). Real-time polymerase chain reaction (PCR) was performed in a 96-well optical reaction plate using SYBR Premix Ex TaqTMII. Reverse transcriptase polymerase chain reactions (RT-PCRs) were performed on Agilent Mx3000P QPCR Systems (Agilent, CA, USA). The levels of mRNA were normalized to the eukaryotic $18 \mathrm{~s}$ rRNA expression level and calculated using the $2(-\Delta \Delta \mathrm{CT})$ method. ${ }^{21}$ The cycling conditions were as follows: initial denaturation at $95^{\circ} \mathrm{C}$ for 30 seconds, followed by 40 cycles at $95^{\circ} \mathrm{C}$ for 5 seconds, $60^{\circ} \mathrm{C}$ for 30 seconds, and $72^{\circ} \mathrm{C}$ for 30 seconds. Primer sequences are available upon request.

\section{Sirt I deacetylase activity assay}

Sirt1 deacetylase activity was colorimetrically measured in vivo and in vitro using the Sirt1 Deacetylase Activity Assay Kit (Genmed Scientifics Inc., Arlington, MA, USA) following the manufacturer's instructions. The kit provided a Sirt1 substrate with an acetylated peptide fragment derived from p53 (which is known to be deacetylated by Sirt1) that was prelabeled with $p$-nitroaniline. After deacetylation by Sirt1, the aminopeptidase cleaved the deacetylated substrate and generated a highly chemiluminescent molecule group of $p$-nitroaniline. The optical densities at a wavelength of $405 \mathrm{~nm}$ were recorded with a spectrophotometer (Diareader ELX800G, Dialab GmbH, Vienna, Austria). Sirtl deacetylation activity was expressed as a percentage of the control.

\section{Statistical analysis}

Data were presented as the mean \pm SD. Statistical analysis was performed by one-way ANOVA. Statistical significance was defined as $P<0.05$.

\section{Results}

Treatment with CTGF siRNA reduced UUO-induced increases in CTGF, the percentage areas of interstitial fibrosis, and ColI, $\alpha$-SMA, PAI-I, and TIMP-I expression, but not TGF- $\beta$ I expression

As shown in Figure 1A, Masson's trichrome staining revealed increased collagen deposition in the kidneys from UUO mice compared with sham mice. We determined the percentage area of interstitial fibrosis in UUO kidneys. The kidneys in the sham treatment group showed very little, if any, fibrosis in the tubules or interstitium. In contrast, the percentage of fibrotic areas in the UUO kidneys was increased compared with the sham group (Figure 1B). We also analyzed total kidney tissue lysates by Western blotting for Coll. As shown in Figure 1C and D, an increase 
A

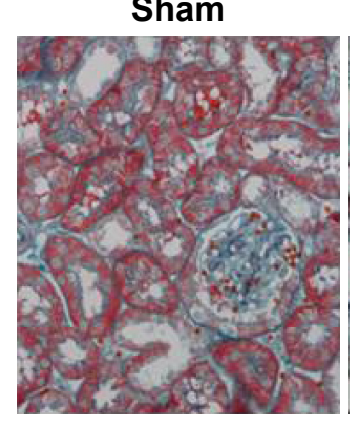

UUO

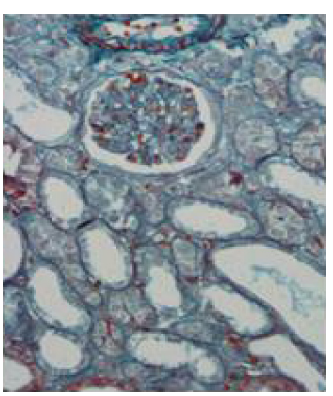

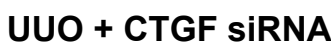

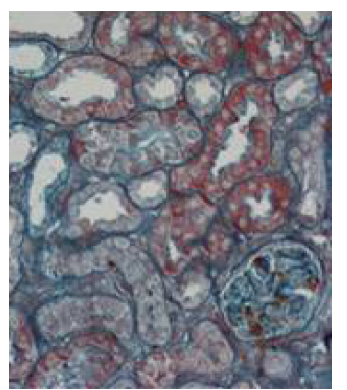

B

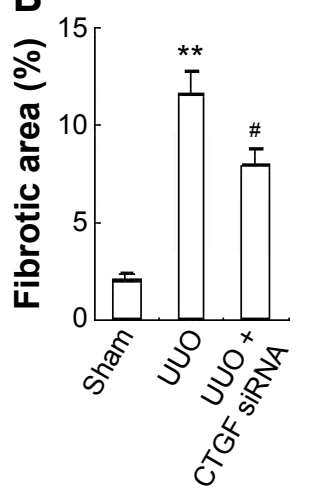

C

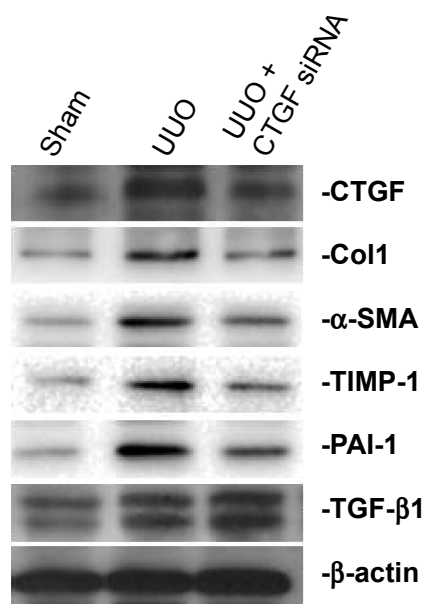

D

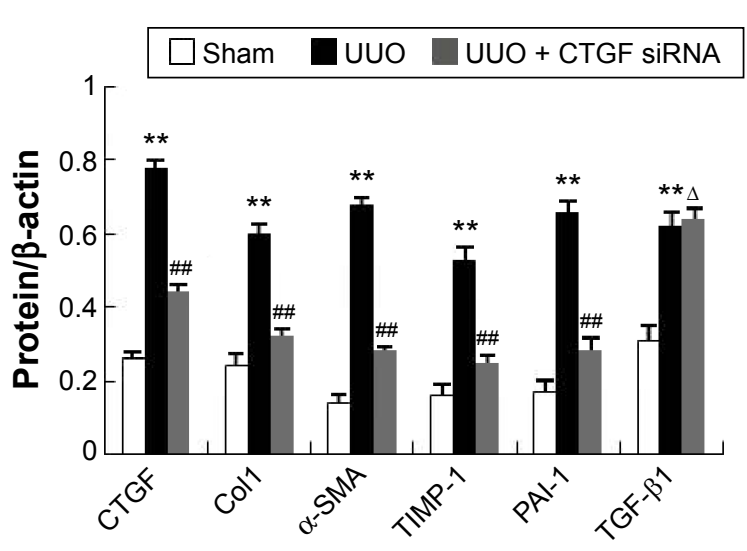

E

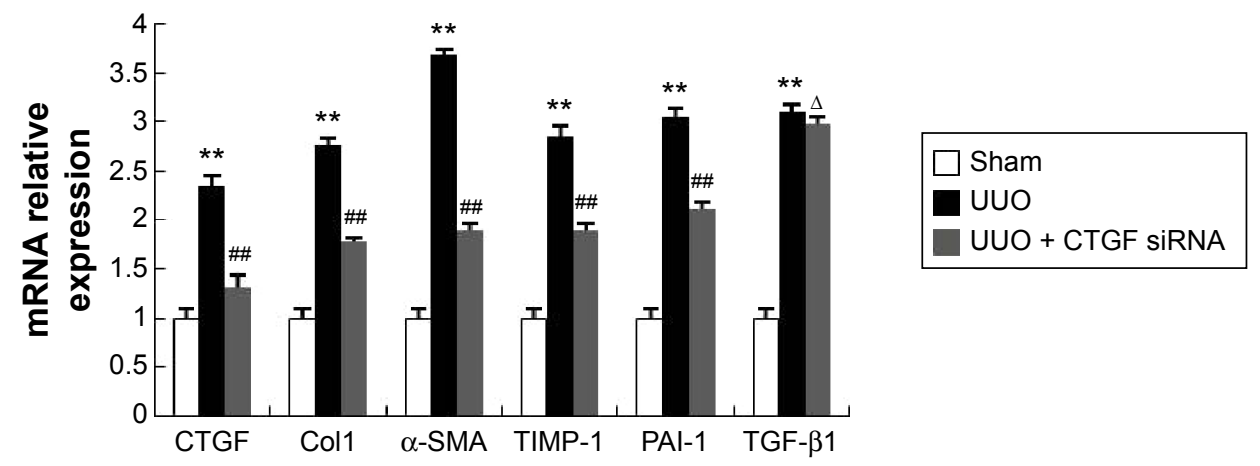

Figure I Treatment with CTGF siRNA plasmid reduced interstitial fibrosis of UUO for 7 days, but not TGF- $\beta$ I.

Notes: (A) Masson's trichrome staining revealed increased collagen deposition in the UUO kidneys compared with sham mice. CTGF siRNA plasmid notably reduced the deposition of UUO kidney. (B) The percentage areas of interstitial fibrosis of sham, UUO, and CTGF siRNA plasmid. (C, D) CTGF siRNA plasmid significantly reduced the protein levels of CTGF, Coll, $\alpha$-SMA, PAI-I, and TIMP-I by Western blot analysis, but not TGF- $\beta$ I. (E) The increases in mRNA expression levels of CTGF, Coll, $\alpha$-SMA, PAI-I, and TIMP-I in UUO were ameliorated by CTGF siRNA plasmid analyzed by real-time RT-PCR. But the increase in TGF- $\beta$ I mRNA was not altered. Values are expressed as mean $\pm S D$. ${ }^{* *} P<0.01$ vs sham; ${ }^{\#} P<0.05$ vs UUO. $(n=6) .{ }^{\Delta}>0.05$ vs UUO. ${ }^{\#} P<0.01$ vs UUO.

Abbreviations: CTGF, connective tissue growth factor; UUO, unilateral ureteral obstruction; Coll, collagen type I; TGF- $\beta$ I, transforming growth factor- $\beta$ I; RT-PCR, reverse transcriptase polymerase chain reaction; SD, standard deviation; vs, versus.

in Coll protein expression was observed in the obstructed kidneys compared with the sham kidneys. Consistent with the result of Col1 protein expression, the Col1 mRNA level was increased in UUO mice (Figure 1E). Moreover, treatment with the CTGF siRNA plasmid resulted in a notably reduced percentage of renal fibrotic areas (Figure 1A and $\mathrm{B}$ ) and Col1 mRNA and protein expression (Figure 1C-E). The delivery of CTGF siRNA to UUO obstructed kidneys did not affect the mRNA and protein levels of TGF- $\beta 1$ (Figure 1C-E). Compared with the UUO group, the mRNA and protein expression did not change in cells treated with control siRNAs (data not shown).

A variety of cytokines are known to affect the processes of interstitial fibrosis (ie, PAI-1 and TIMP-1). $\alpha$-SMA is a molecular hallmark of fibroblast activation during the fibroblast-to-myofibroblast transition. Therefore, we 
examined the levels of PAI-1, TIMP-1, and $\alpha$-SMA in vivo. The mRNA and protein levels of PAI-1, TIMP-1, and $\alpha-S M A$ detected by Western blotting and real-time RT-PCR were all significantly increased in the obstructed kidneys of the UUO group compared with the CTGF siRNA plasmid transfection group and the sham group (Figure $1 \mathrm{C}-\mathrm{E}$ ). Moreover, immunohistochemistry (Figure 2) indicated that areas staining positive for PAI-1, TIMP-1, and $\alpha$-SMA were located mainly in tubular epithelial cells from the UUO kidneys, and that the delivery of CTGF siRNA greatly downregulated the expression of PAI-1, TIMP-1, and $\alpha$-SMA. Compared with the UUO group, the mRNA and protein expression did not change in cells treated with control siRNAs (data not shown).

\section{Treatment with CTGF siRNA attenuated the UUO-induced increase in Bax expression, apoptosis rate, and decrease in $\mathrm{Bcl}-2$ expression}

The number of tubular epithelial cells containing TUNELpositive nuclei was increased in UUO mice compared with sham mice; this increase was markedly decreased by the delivery of CTGF siRNA (Figure 3A-D). Furthermore, in the obstructive kidney UUO group, 7 days of UUO resulted in a significant decrease in Bcl-2 protein and mRNA expression compared with the sham operation kidney group. In contrast, Bax mRNA and protein levels were significantly increased in the obstructive kidney UUO group. Administration of CTGF siRNA attenuated the changes in Bcl-2 and Bax expression (Figure 3E-G). Compared with the UUO group, the mRNA and protein expression did not change in cells treated with control siRNAs (data not shown).

\section{rhCTGF increased $\alpha$-SMA, TIMP-I, PAI-I, and Coll expression, and decreased E-cad expression in HK-2 cells}

In the following in vitro experiments, we determined whether CTGF was the direct inducer of EMT, interstitial matrix accumulation, and interstitial fibrosis in HK-2 cells. The EMT was identified by the observation of dramatical downregulation of E-cad that is expressed in epithelial cells only, and
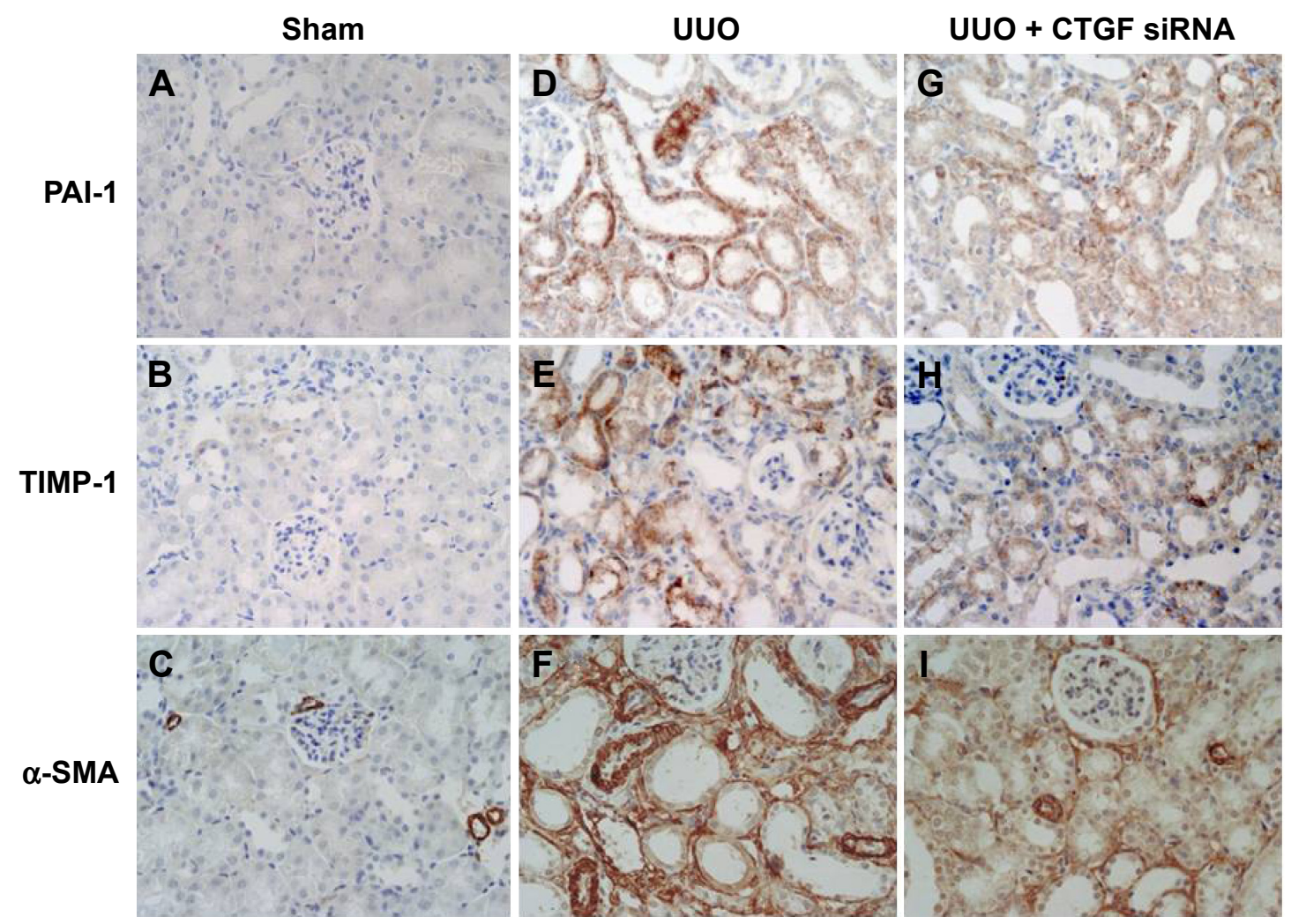

Figure 2 Delivery of CTGF siRNA plasmid greatly downregulated the protein expressions of PAI-I, TIMP-I, and $\alpha$-SMA in UUO kidney at day 7 post-UUO by immunohistochemistry study.

Notes: (A-C) in sham group. (D-F) Immunohistochemistry study indicated that the positive staining was mainly found in tubular epithelial cells in UUO kidney. (G-I) Treatment of CTGF siRNA plasmid significantly attenuated the expression in UUO kidney.

Abbreviations: CTGF, connective tissue growth factor; UUO, unilateral ureteral obstruction. 

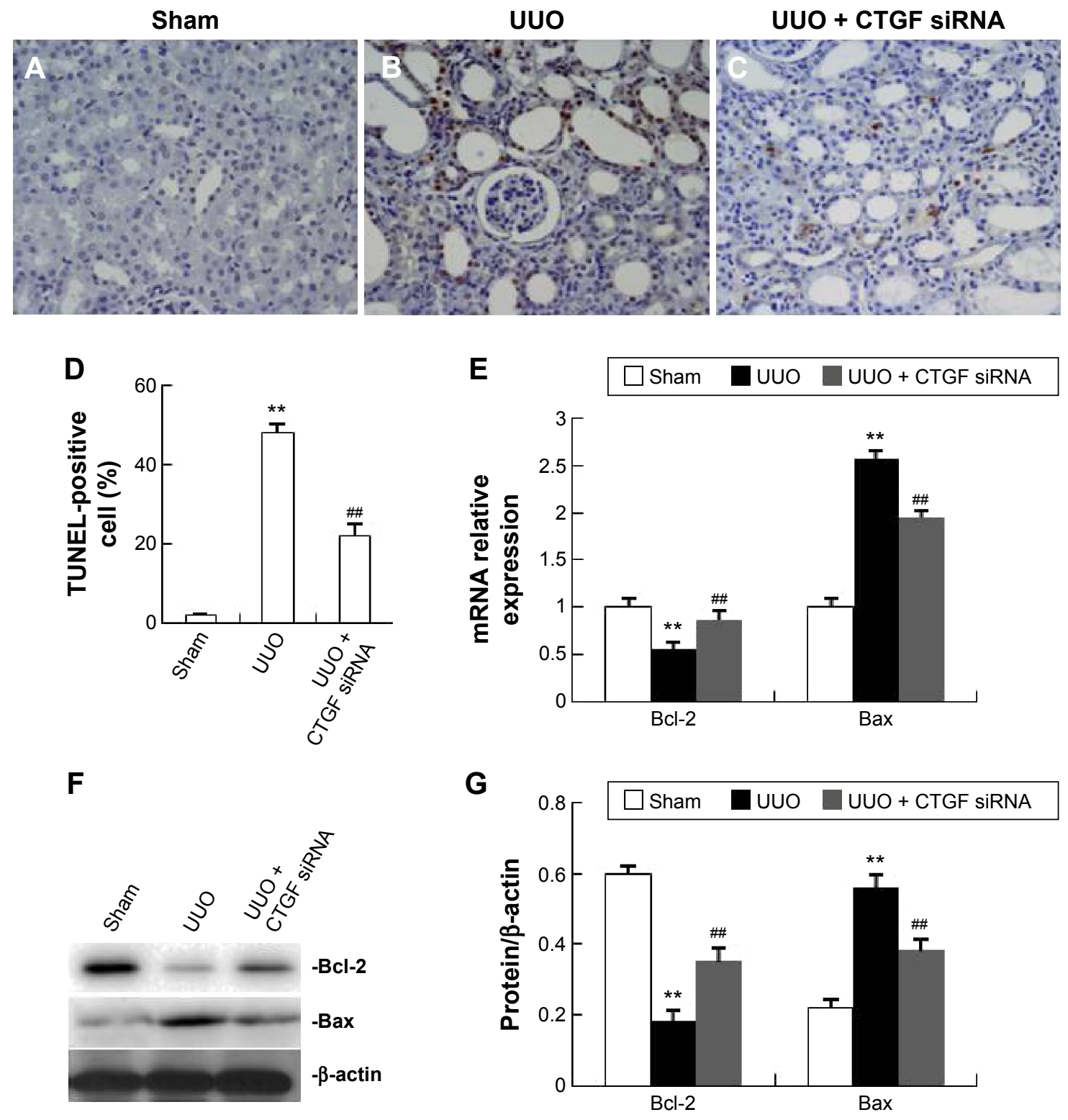

Figure 3 Treatment with CTGF siRNA plasmid attenuated apoptosis at day 7 post-UUO.

Notes: The number of tubular epithelial cells containing TUNEL-positive nuclei was increased in UUO kidneys (B) compared with sham kidneys (A), which was markedly decreased by the delivery of CTGF siRNA plasmid (C). The percentage of TUNEL-positive cells in different groups (D). Real-time RT-PCR analysis (E) and Western blot analysis $(\mathbf{F}, \mathbf{G})$ revealed the significant decrease in mRNA expression and protein of $\mathrm{Bcl}-2$, and increase in Bax compared with the sham operation kidney, whereas, CTGF siRNA plasmid administration attenuated the changes in $B c l-2$ and Bax. Values are expressed as mean $\pm S D$. ${ }^{*} * P<0.01$ vs sham; ${ }^{*} P<0.01$ vs $U U O$. ( $(n=6)$.

Abbreviations: TUNEL, TdT-dUTP nick end labeling; CTGF, connective tissue growth factor; UUO, unilateral ureteral obstruction; RT-PCR, reverse transcriptase polymerase chain reaction; SD, standard deviation; vs, versus.

upregulation of $\alpha$-SMA and CTGF as mensenchymal-specific features. When HK-2 cells were treated with recombinant human CTGF (rhCTGF), the mRNA levels of $\alpha$-SMA, TIMP-1, PAI-1, and Col1 were significantly increased, and E-cad was decreased compared with the NG (Figure 4E). Western blotting showed that the protein levels of $\alpha$-SMA, TIMP-1, PAI-1, and Col1 were all greatly elevated after stimulation with rhCTGF, while the E-cad protein level was significantly downregulated (Figure 4C and D).

\section{rhCTGF increased the apoptosis rate} and Bax expression, and decreased $\mathrm{Bcl}-2$ expression in HK-2 cells

To detect the direct effect of rhCTGF on apoptosis, the cells were cultured in DMEM-F12 medium containing rhCTGF for 24 hours. rhCTGF treatment significantly promoted the cell apoptosis rate examined by TUNEL, Hoechst 33258 staining, and FCM compared with the control group (Figure 4A and B). Next, we examined whether the rhCTGF-induced cell 

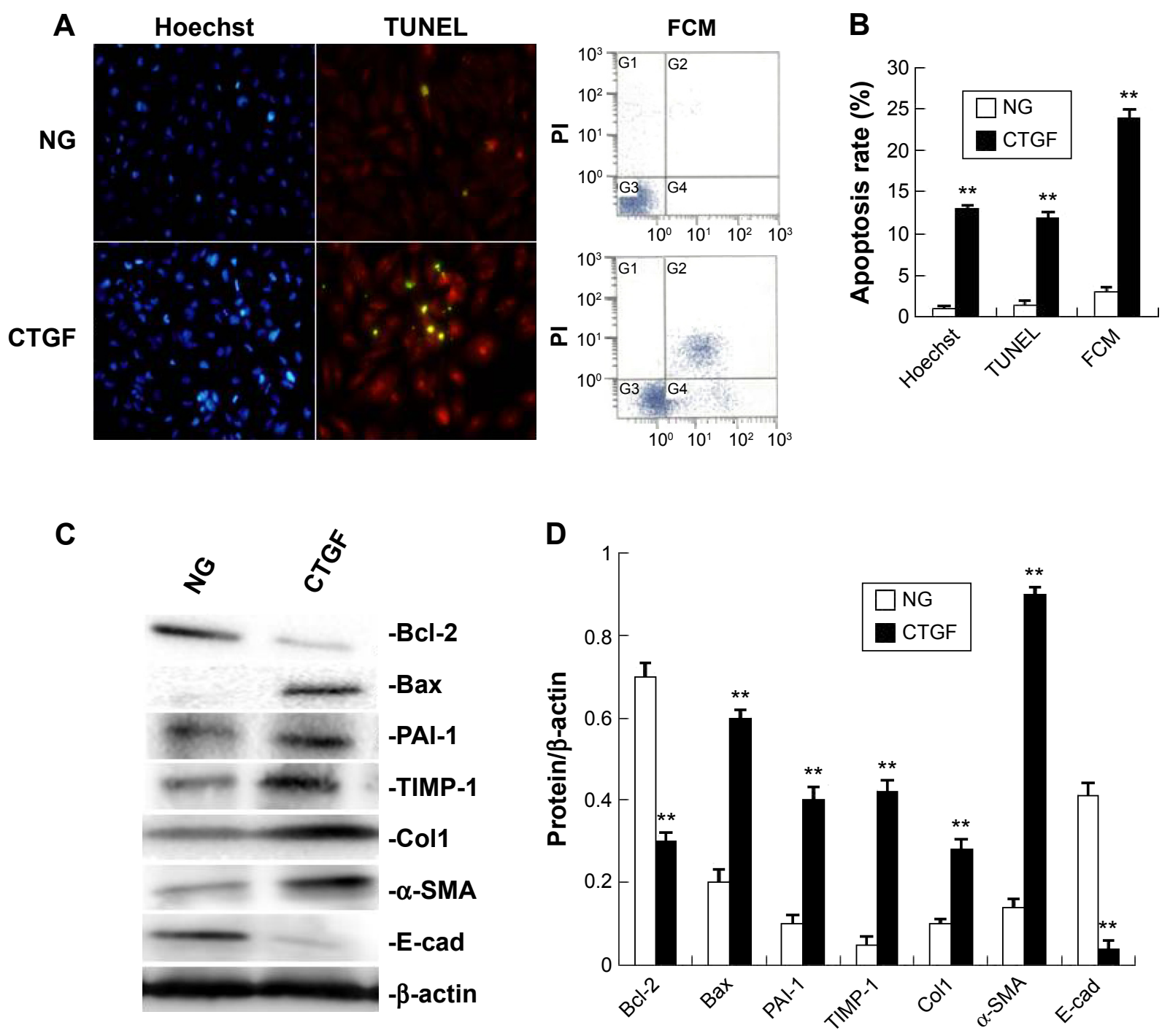

$\mathbf{E}$

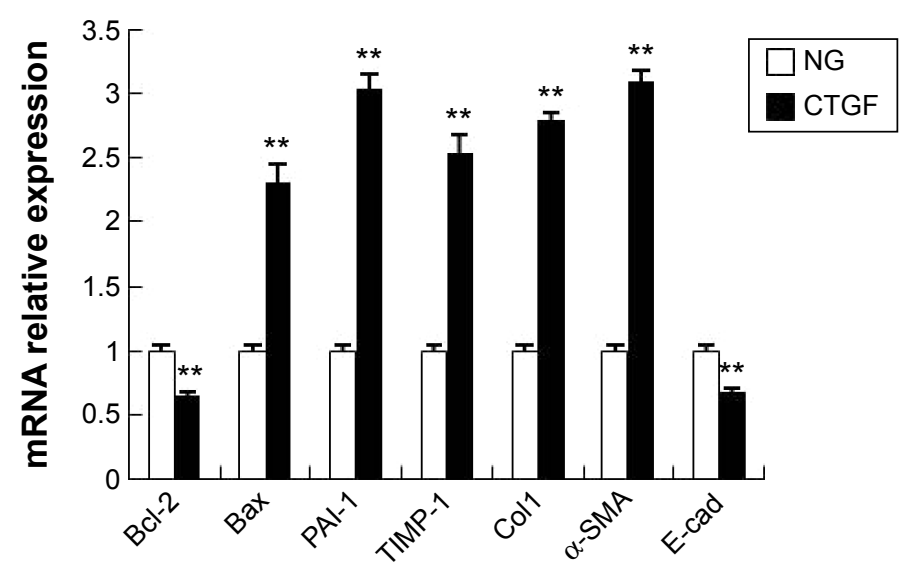

Figure 4 rhCTGF (I0 ng/mL) directly increased apoptosis, $\alpha$-SMA, TIMP-I, PAI-I, and Coll, and decreased E-cad in HK-2 cells for 24 hours.

Notes: (A) rhCTGF significantly promoted cell apoptosis rate examined by TUNEL, Hoechst 33258 staining, and FCM. (B) The percentage of apoptosis cells in different groups detected by different methods. (C, D) The changes in proteins of Bcl-2, Bax, $\alpha$-SMA, TIMP-I, PAI-I, Coll, and E-cad were observed by Western blot. (E) Real-time RT-PCR analysis showed the changes in mRNAs of Bcl-2, Bax, $\alpha$-SMA, TIMP-I, PAI-I, Coll, and E-cad induced by rhCTGF. Values are expressed as mean \pm SD. $* * P<0.0 \mathrm{I}$ vs NG. $(n=6)$.

Abbreviations: TUNEL, TdT-dUTP nick end labeling; NG, normal group; CTGF, connective tissue growth factor; FCM, flow cytometer; PI, propidium iodide; Coll, collagen type I; rhCTGH, recombinant human CTGH; RT-PCR, reverse transcriptase polymerase chain reaction; SD, standard deviation. 
apoptosis was linked to the expression of Bax and Bcl-2. As shown in Figure 4C-E, rhCTGF upregulated the expression of the Bax mRNA and protein compared with the NG, whereas it inhibited the expression of Bcl-2 (Figure 2).

\section{Transfection of CTGF siRNA altered the increased expression of CTGF, $\alpha$-SMA, TIMP-I, PAI-I, and Coll, and decreased the expression of E-cad via stimulation of TGF- $\beta$ I in HK-2 cells}

We found that the expression of the CTGF protein was increased in HK-2 cells in the rhTGF- $\beta 1$-stimulated group (Figure 5A and B). rhTGF- $\beta 1$ also increased CTGF mRNA levels (Figure 5C). Western blot analysis revealed that CTGF expression was significantly decreased after treatment with CTGF siRNA (Figure 5A and B). Furthermore, we analyzed the role of CTGF in the rhTGF- $\beta 1$-induced increases of fibrogenesis-associated factors. Administration of CTGF siRNA markedly attenuated the increase in the mRNA and protein levels of $\alpha$-SMA, TIMP-1, PAI-1, and Col1, and decreased the level of E-cad stimulated by rhTGF- $\beta 1$ (Figure 5). Compared with the TGF- $\beta 1$ group, the mRNA and protein expression did not change in cells treated with control siRNAs (data not shown).

\section{Transfection of CTGF siRNA inhibited the increase in the apoptosis rate and Bax expression, and the decrease in $\mathrm{Bcl}-2$ expression via stimulation of TGF- $\beta$ I in HK-2 cells}

As shown in Figure 6A and B, exposure to rhTGF- $\beta 1$ significantly increased cell apoptosis compared with NG. This increase was efficiently inhibited by transfection with CTGF siRNA as detected by FCM. As shown in Figure 6C-E, rhTGF- $\beta 1$ stimulation of HK-2 cells for 24 hours decreased Bcl-2 levels and increased Bax levels compared with their expression levels in normal medium. Compared with the cells treated with rhTGF- $\beta 1$, delivery of CTGF siRNA
A

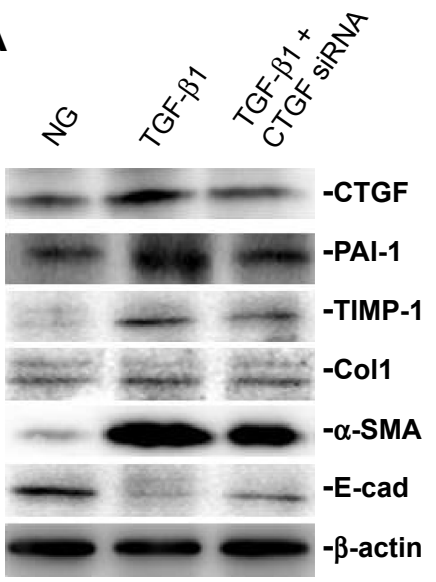

B

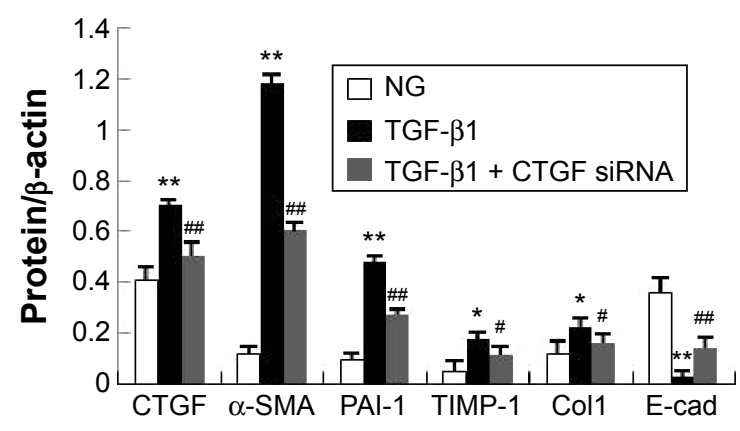

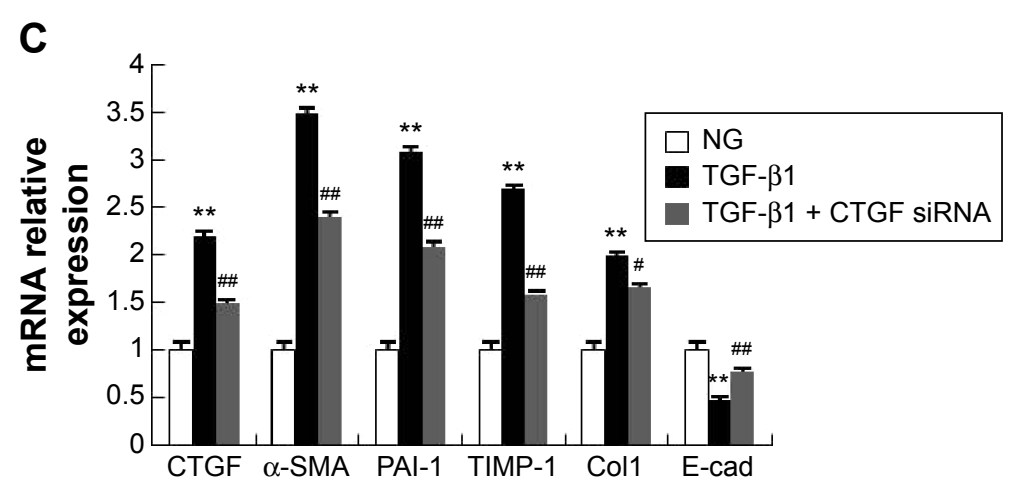

Figure 5 Transfection of CTGF siRNA altered the increases in CTGF, $\alpha-S M A$, TIMP-I, PAI-I, and Coll, and the decrease in E-cad expression via stimulation of rhTGF- $\beta$ I $(5 \mathrm{ng} / \mathrm{mL})$ for 24 hours in HK-2 cells.

Notes: rhTGF- $\beta$ I increased the protein (A, B) and mRNA levels of CTGF (C). We transfected cells with the CTGF siRNA plasmid in the presence of rhTGF- $\beta$ I. Administration of the CTGF siRNA plasmid markedly attenuated the increase in mRNA (C) and protein (A, B) levels of $\alpha$-SMA, TIMP-I, PAI-I, and Coll, and the decrease of E-cad stimulated by rhTGF- $\beta$ I. Values are expressed as mean \pm SD. $* * P<0.0$ I vs NG; ${ }^{*} P<0.01$ vs TGF- $\beta$ I; ${ }^{*} P<0.05$ vs TGF- $\beta$ I. ( $n=6$ ). ${ }^{*} P<0.05$ vs $N G$.

Abbreviations: NG, normal group; TGF- $\beta$ I, transforming growth factor- $\beta$ I; CTGF, connective tissue growth factor; Coll, collagen type I; rhTGF- $\beta$ I, recombinant human TGF- $\beta$ I; SD, standard deviation; vs, versus. 


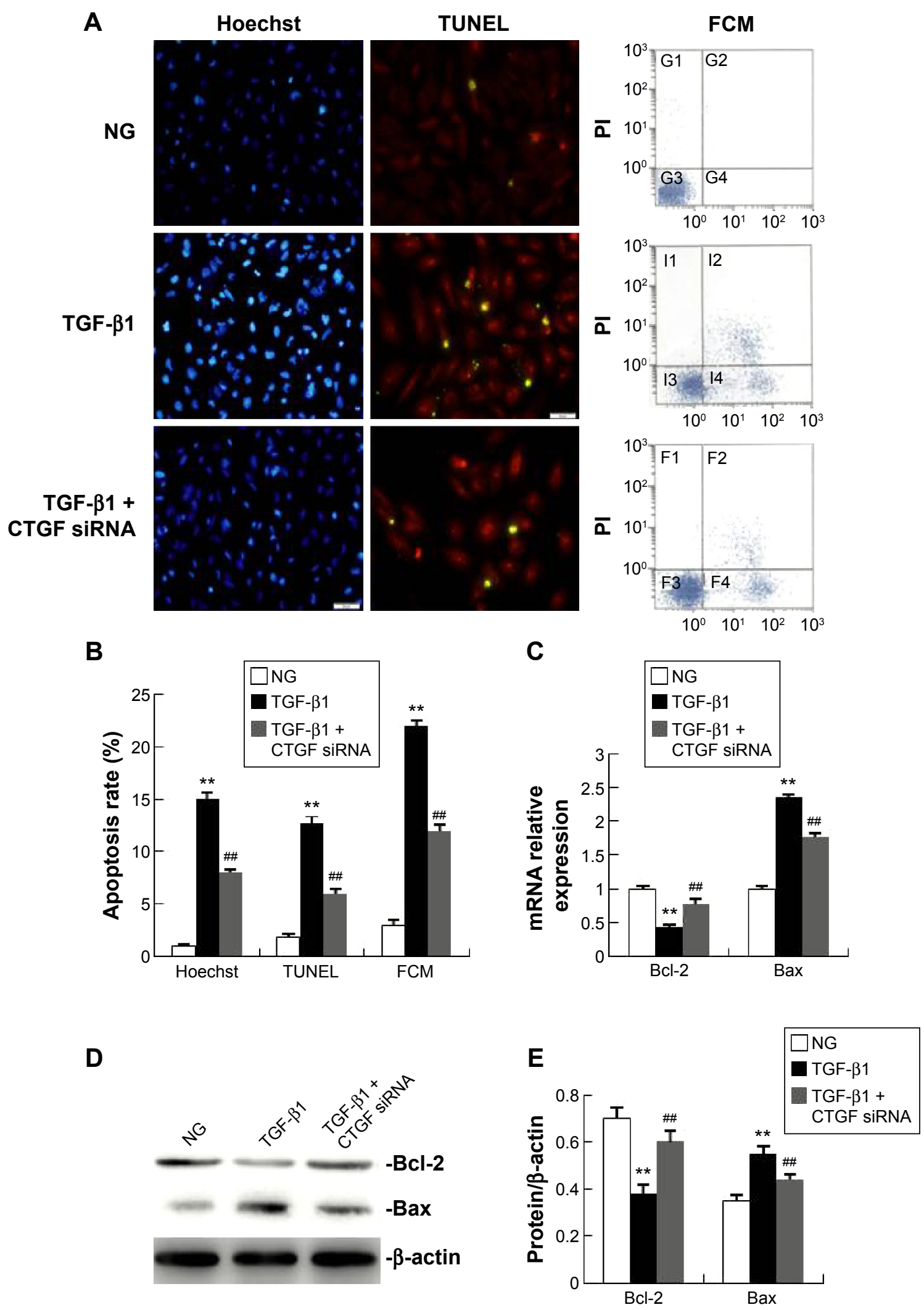

Figure 6 Transfection of CTGF siRNA inhibited apoptosis via stimulation of rhTGF- $\beta$ I $(5 \mathrm{ng} / \mathrm{mL})$ for 24 hours in HK- 2 cells.

Notes: (A) CTGF siRNA significantly inhibited the rhTGF- $\beta$ I-induced cell apoptosis rate examined by TUNEL, Hoechst 33258 staining, and FCM. The percentage of apoptotic cells in the different groups detected by different methods (B). (C) Real-time RT-PCR analysis showed the changes in Bcl-2 and Bax mRNA levels. (D, E) The changes in $\mathrm{Bcl}-2$ and Bax protein levels were detected by Western blotting. Values are expressed as mean \pm SD. $* * P<0.01$ vs NG; $\# P<0.01$ vs TGF- $\beta$ I. ( $n=6$ ).

Abbreviations: TUNEL, TdT-dUTP nick end labeling; NG, normal group; TGF- $\beta$ I, transforming growth factor- $\beta$ I; $C T G F$, connective tissue growth factor; FCM, flow cytometer; PI, propidium iodide; rhTGF- $\beta$ I, recombinant human TGF- $\beta$ I; RT-PCR, reverse transcriptase polymerase chain reaction; SD, standard deviation; vs, versus. 
significantly ameliorated the decrease in Bcl-2 and the increase in Bax. Compared with the TGF- $\beta 1$ group, the mRNA and protein expression did not change in cells treated with control siRNAs (data not shown).

\section{Delivery of CTGF siRNA did not affect the decrease in Sirtl induced by UUO in vivo or TGF- $\beta$ I in vitro}

Figure 7A-C shows the decrease in the Sirt1 protein and mRNA levels in UUO kidneys. Likewise, Sirt1 activity was significantly decreased in UUO kidneys compared with the sham kidneys (Figure 7C). Sirt1 mRNA and protein levels were not altered by the delivery of CTGF siRNA compared with the UUO kidney (Figure 7A-C). There was also no difference in Sirt1 deacetylase activity between the UUO group and the CTGF siRNA plasmid group (Figure 7D). Next, we examined Sirt1 expression in TGF- $\beta 1$-stimulated HK-2 cells. Sirt1 expression was confirmed to be decreased in the TGF- $\beta 1$ group compared with the NG by immunocytochemistry (Figure 8A and B). Delivery of CTGF siRNA did not ameliorate the decrease of Sirt1 positive staining in vitro (Figure 8C). Concordantly, Sirt1 mRNA and protein levels measured by real-time RT-PCR and Western blotting were both decreased after TGF- $\beta 1$ stimulation (Figure $8 \mathrm{D}-\mathrm{F}$ ); as expected, Sirt1 activity was also markedly decreased (Figure $8 \mathrm{G}$ ). Furthermore, Sirt1 mRNA, protein levels, and deacetylase activity were not altered by the delivery of CTGF siRNA compared with rhTGF- $\beta 1$-stimulated HK-2 cells (Figure $8 \mathrm{D}-\mathrm{G}$ ). Compared with the TGF- $\beta 1$ group, the Sirt1 expression did not change in cells treated with control siRNAs (data not shown).

\section{Overexpression of Sirt I ameliorates TGF- $\beta$ I-induced increases in CTGF, $\alpha$-SMA, TIMP-I, PAI-I, and Coll, and decrease in E-cad expression in HK-2 cells}

The overexpression of Sirt1 in HK-2 cells was confirmed by Western blotting (Figure 9A and B). The Sirt1 activity assay demonstrated that the overexpression of Sirt1 significantly increased Sirt1 deacetylase activity (Figure 9C). Western blotting and real-time RT-PCR both showed that HK-2 cells overexpressing Sirt1 significantly attenuated rhTGF$\beta 1$-induced increases in $\alpha$-SMA, TIMP-1, PAI- 1 , and Col1, and the decrease in E-cad expression at 24 hours compared with the rhTGF- $\beta 1$-stimulated group (Figure 9D-F), supporting the protective effect of Sirt1 on renal fibrosis. Sirt1 overexpression attenuated the increase in CTGF expression at the protein level by Western blotting analysis (Figure 9D and E) and the mRNA level based on real-time RT-PCR analysis (Figure 9F) in rhTGF- $\beta 1$-induced HK-2 cells. Compared with the TGF- $\beta 1$ group, the mRNA and protein expression
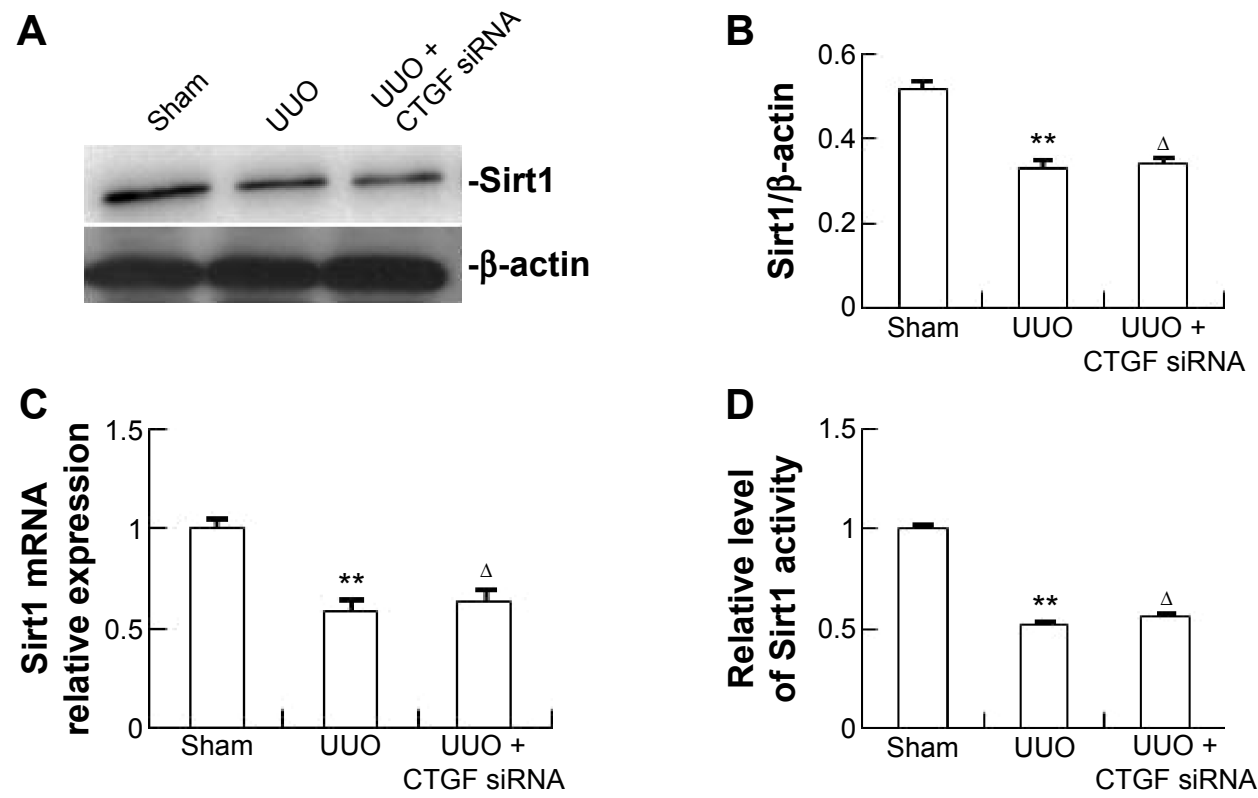

Figure 7 Delivery of the CTGF siRNA plasmid did not affect the decrease in Sirtl induced by UUO for 7 days in vivo.

Notes: Sirt I protein (A, B), mRNA (C), and activity (D) were all significantly decreased in the UUO kidneys compared with the sham kidneys; delivery of the CTGF siRNA plasmid did not alter the reduction. Values are expressed as mean $\pm S D$. ${ }^{*} * P<0.01$ vs sham; ${ }^{\triangle P}>0.05$ vs $U U O$. ( $\left.n=6\right)$.

Abbreviations: CTGF, connective tissue growth factor; UUO, unilateral ureteral obstruction; Sirt I, mammalian sirtuin I; SD, standard deviation; vs, versus. 

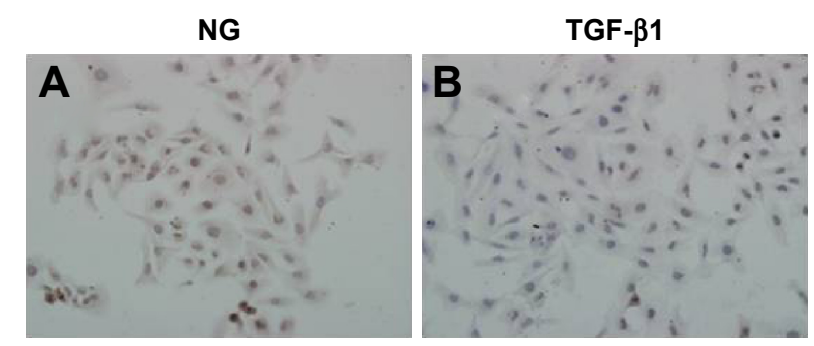

TGF-ß1 + CTGF siRNA
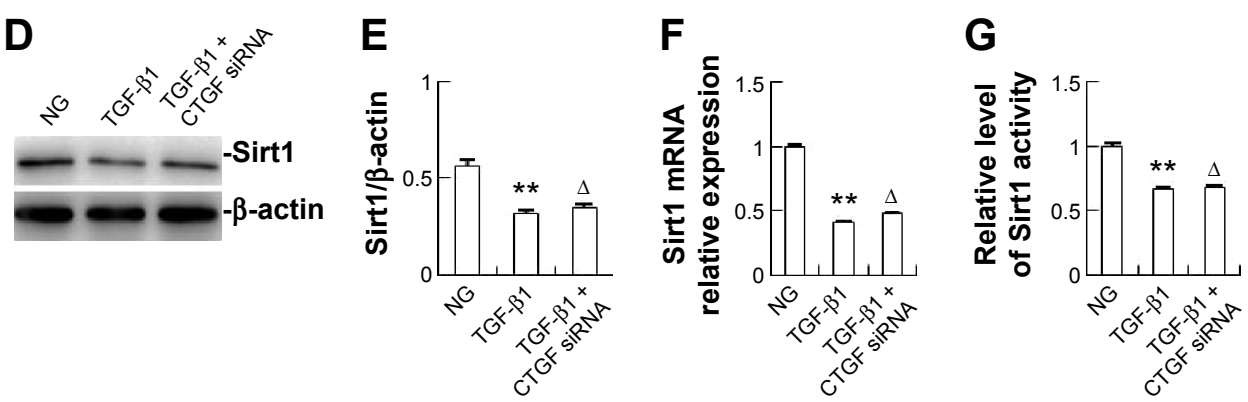

Figure 8 Delivery of the CTGF siRNA plasmid did not affect the decrease in Sirtl expression induced by rhTGF- $\beta$ I ( $5 \mathrm{ng} / \mathrm{mL})$ for 24 hours in vitro.

Notes: Immunocytochemistry showed that Sirt I was widely localized in the cytoplasm of renal tubular cells in normal group HK-2 cells (A). Sirt I expression was dramatically decreased in the rhTGF- $\beta$ I stimulation group (B). Delivery of the CTGF siRNA plasmid did not ameliorate the decrease of Sirt I (C). Western blotting (D, E); Sirt I mRNA and protein were both decreased after rhTGF- $\beta$ I stimulation measured by real-time RT-PCR (F). Sirt I activity (G) was also markedly decreased. Delivery of the CTGF siRNA plasmid did not alter the reduction. Values are expressed as mean \pm SD. ${ }^{* *} P<0.0$ I vs sham; ${ }^{\Delta P}>0.05$ vs $T G F-\beta$ I. ( $n=6$ ).

Abbreviations: NG, normal group; TGF- $\beta$ I, transforming growth factor- $\beta$ I; CTGF, connective tissue growth factor; Sirt I, mammalian sirtuin I; rhTGF- $\beta$ I, recombinant human TGF- $\beta$ I; RT-PCR, reverse transcriptase polymerase chain reaction; SD, standard deviation; vs, versus.

did not change in cells treated with control siRNAs (data not shown).

\section{Overexpression of Sirt I reduces the rhTGF- $\beta$ I-induced increase in the apoptosis rate and Bax expression and decreased $\mathrm{Bcl}-2$ expression in $\mathrm{HK}-2$ cells}

As shown in Figure 10A and B, the percentage of apoptotic cells in the rhTGF- $\beta 1 \mathrm{HK}-2$ cell group at 24 hours was increased significantly compared with the NG. The administration of Sirt1 overexpression significantly reduced the percentages of apoptotic cells induced by rhTGF- $\beta 1$. As shown in Figure 10C-E, Sirt1 overexpression increased Bcl-2 protein and mRNA levels, and decreased Bax protein and mRNA levels. Compared with the TGF- $\beta 1$ group, the mRNA and protein expression did not change in cells treated with control siRNAs (data not shown).

\section{Discussion}

Renal fibrosis inevitably progresses to end-stage renal disease with a progressive, irreversible decline in renal function, regardless of whether the origin is inflammatory or immunological, obstructive, metabolic, or systemic. ${ }^{22}$ To the best of our knowledge, in this study, we have provided the first evidence that the in vivo delivery of CTGF siRNA ameliorated tubular cell apoptosis and tubulointerstitial fibrosis in obstructed mouse kidneys. Our in vitro data also suggest the possible involvement of Sirt1 in the profibrotic action of CTGF in the presence of rhTGF- $\beta 1$.

The pathogenesis of renal fibrosis has been depicted as a continuum of four overlapping phases: priming (localized inflammatory response), activation (activation and recruitment of matrix producing cells), execution (accumulation of matrix protein), and progression (loss of cells and renal function). ${ }^{23}$ CTGF and TGF- $\beta$, key mediators of kidney fibrosis, were identified on the basis of their contribution to these phases. CTGF is a cysteine-rich matricellular protein belonging to the $\mathrm{CCN}$ family of proteins, which have many diverse functions in processes such as angiogenesis, fibrosis, and apoptosis. TGF- $\beta$, a ubiquitously expressed cytokine, has also been demonstrated to promote tissue repair, but its excessive expression can mediate diverse profibrotic events in the liver, ${ }^{24}$ lung, ${ }^{25}$ kidney, ${ }^{26}$ and breast. ${ }^{27}$ CTGF enhances TGF- $\beta$ signaling and facilitates TGF- $\beta$ binding to TGF- $\beta$ receptors. ${ }^{28}$ Moreover, correlative studies in humans and animals with tissue fibrosis support a link between CTGF and TGF- $\beta$. Most models postulate that CTGF acts either downstream or cooperatively with TGF- $\beta .^{29,30}$ In this study, we found that the expression of CTGF and TGF- $\beta 1$ were both increased in UUO obstructed kidneys and that rhTGF- $\beta 1(5 \mathrm{ng} / \mathrm{mL})$ treatment of HK-2 cells for 24 hours remarkably increased CTGF levels. In turn, this increase was accompanied by a 
A

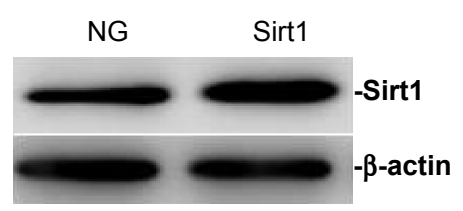

D

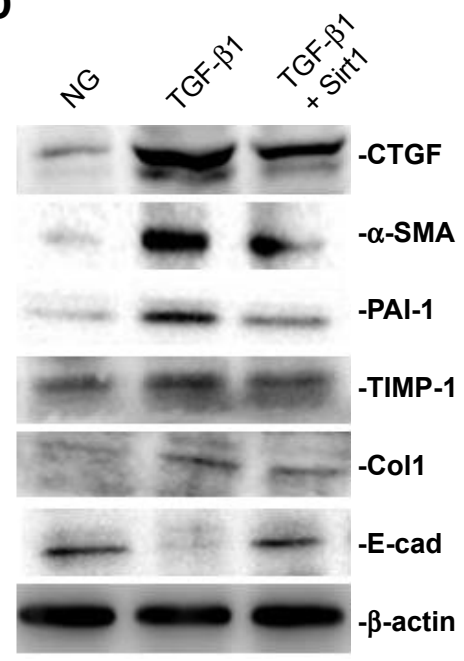

B

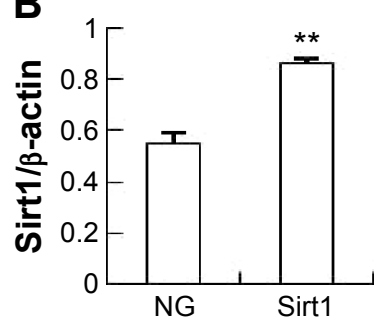

E

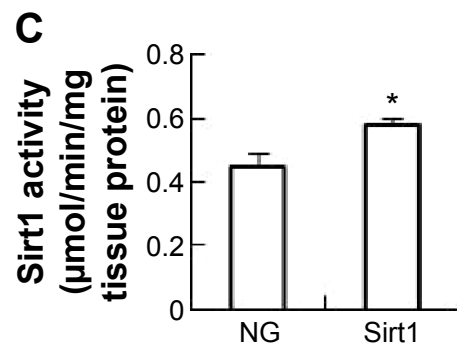

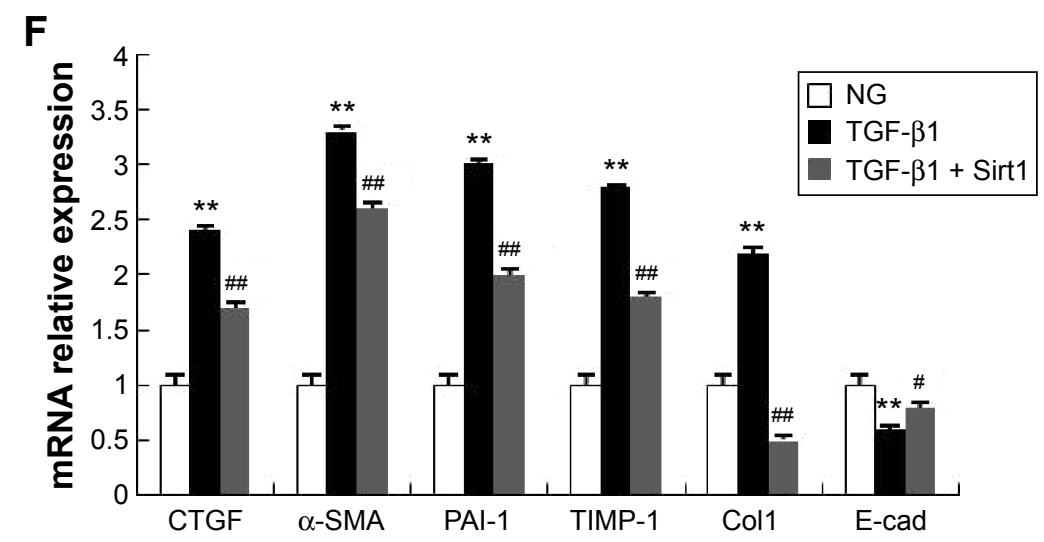

Figure 9 Overexpression of Sirt I ameliorates increases in CTGF, $\alpha$-SMA, TIMP-I, PAI-I, and Coll and the decrease in E-cad expression treated with rhTGF- $\beta$ I (5 ng/mL) for 24 hours in HK-2 cells.

Notes: The overexpression of Sirtl in HK-2 cells was confirmed by Western blotting (A, B). The Sirtl activity assay demonstrated that the overexpression of Sirt I significantly increased Sirt I deacetylase activity (C). (D, E) Overexpression of Sirt I significantly reduced the protein levels of CTGF, Coll, $\alpha$-SMA, PAI-I, and TIMP-I stimulated by rhTGF- $\beta$ I. (F) The increases in mRNA expression levels of CTGF, Coll, $\alpha-S M A$, PAI-I, and TIMP-I induced by rhTGF- $\beta$ I were ameliorated by SirtI overexpression. Values are expressed as mean \pm SD. $* * P<0.0$ I vs NG; $* P>0.05$ vs $N G ;{ }^{*} P<0.0$ I vs TGF- $\beta$ I. $(n=6)$. ${ }^{*} P<0.05$ vs TGF- $\beta$ I. $(n=6)$.

Abbreviations: NG, normal group; TGF- $\beta$ I, transforming growth factor- $\beta$ I; Coll, collagen type I; CTGF, connective tissue growth factor; SirtI, mammalian sirtuin I; rhTGF- $\beta$ I, recombinant human TGF- $\beta$ I; SD, standard deviation; vs, versus.

significant upregulation of matrix accumulation, EMT, and apoptosis. This result is consistent with the observation that the expression of TGF- $\beta$ and CTGF is increased in human and experimental models of chronic kidney disease and correlates with the severity of renal fibrosis. . $2,31-33^{-3}$

We used siRNA targeting to silence the CTGF gene, which is a valuable tool for investigating the function of gene products in tissues. To the best of our knowledge, this is the first report to show the effect of delivery of CTGF siRNA to a UUO mouse kidney. In this study, delivery of CTGF siRNA effectively downregulated the expression of CTGF in UUO kidneys in a sequence-specific manner, causing significant inhibition of tubular cell apoptosis and tubulointerstitial fibrosis. TGF- $\beta 1$ is a potent inducer of CTGF, and CTGF acts 

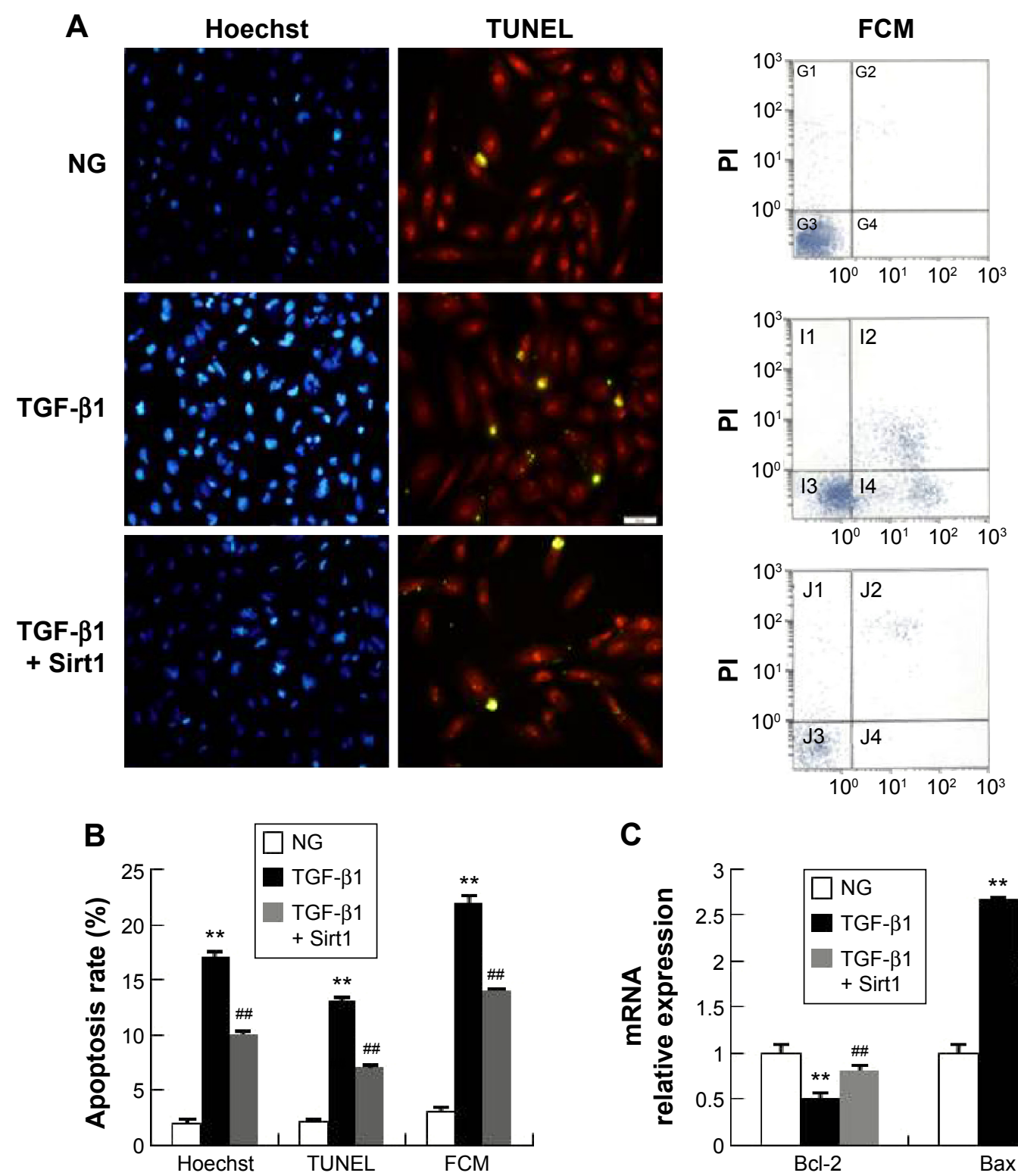

C

D

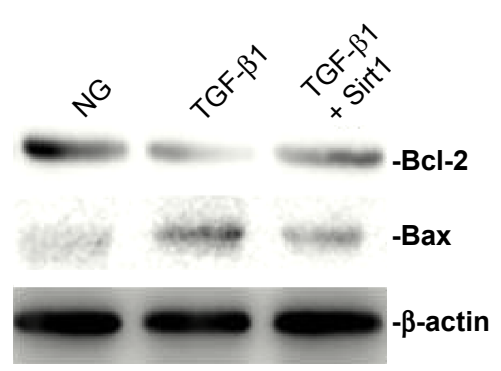

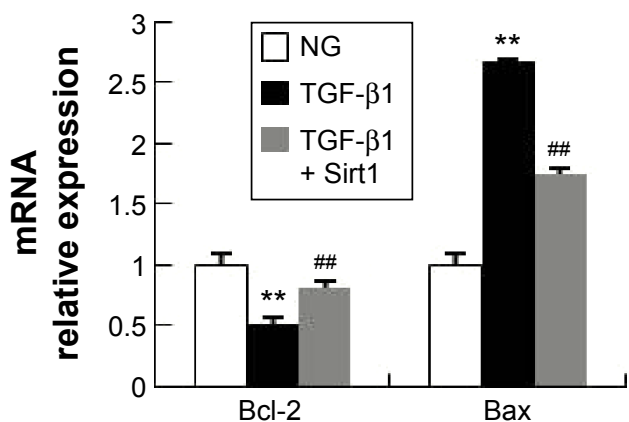

E

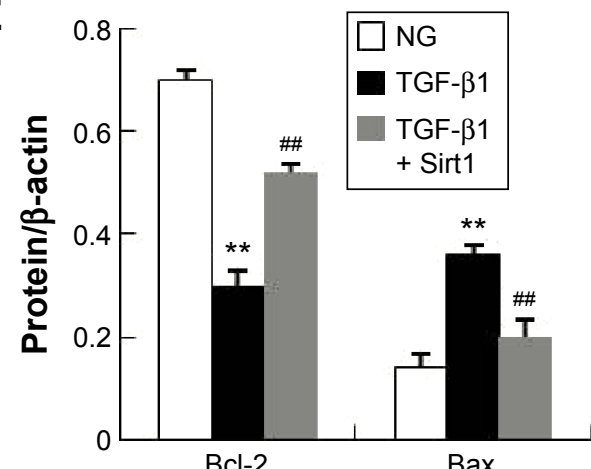

Figure 10 Overexpression of Sirtl reduced increases in the apoptosis rate and Bax expression and decrease in Bcl-2 expression in HK-2 cells after rhTGF- $\beta$ I (5 ng/mL) treatment for 24 hours.

Notes: (A) Sirt l overexpression significantly inhibited the rhTGF- $\beta$ I-induced cell apoptosis rate examined by TUNEL, Hoechst 33258 staining, and FCM. The percentage of apoptotic cells in different groups detected by different methods (B). (C) Real-time RT-PCR analysis demonstrated changes in Bcl-2 and Bax mRNAs levels. (D, E) Changes in $\mathrm{Bcl}-2$ and Bax protein levels observed by Western blotting. Values are expressed as mean \pm SD. $* * P<0.01$ vs $N G$; $\# P<0.0$ I vs TGF- $\beta$ I. ( $n=6$ ).

Abbreviations: TUNEL, TdT-dUTP nick end labeling; NG, normal group; TGF- $\beta$ I, transforming growth factor- $\beta$ I; Sirtl, mammalian sirtuin I; FCM, flow cytometer; PI, propidium iodide; rhTGF- $\beta$ I, recombinant human TGF- $\beta$ I; RT-PCR, reverse transcriptase polymerase chain reaction; SD, standard deviation; vs, versus. 
downstream of TGF- $\beta 1$ to promote fibrosis. Not surprisingly, TGF- $\beta 1$ expression was not altered following CTGF siRNA plasmid treatment in obstructive kidneys after 7 days.

The elucidation of the molecular mechanisms of the profibrotic action of CTGF may provide clues to understand the pathogenesis of renal fibrosis associated with TGF- $\beta 1$. Growing evidence has revealed that sirtuins (NAD-dependent protein deacetylases) play a regulatory role in the process of different renal diseases. The antifibrotic function of Sirt1 has been reported in patients with heart failure, ${ }^{34}$ cardiac fibrosis, ${ }^{35}$ hepatic steatosis, ${ }^{36}$ diabetic nephropathy, ${ }^{37}$ and UUO. ${ }^{17}$ In this study, we found that Sirt1 expression and activity were both dramatically decreased in UUO obstructed mouse kidneys. Recently, growing evidence has shown that Sirt1 is associated with TGF- $\beta$ in endothelial cells, ${ }^{38}$ vascular smooth muscle cells, ${ }^{39}$ bronchial epithelial cells, ${ }^{40}$ and mesangial cells. ${ }^{15}$ Moreover, Sirt1 overexpression attenuated TGF- $\beta 1$-induced extracellular matrix expression in cultured mesangial cells. ${ }^{15}$ Studies have suggested that the TGF- $\beta 1$-Smad-SIRT6 pathway may play a critical role in the regulation of vascular smooth muscle cells differentiation in response to the cyclic strain. ${ }^{39}$ Indeed, the overexpression of Sirt6 efficiently inhibited TGF- $\beta 1$-induced senescence in idiopathic pulmonary fibrosis. ${ }^{40}$ Therefore, we treated cultured HK-2 cells with rhTGF- $\beta 1(5 \mathrm{ng} / \mathrm{mL})$ to determine the role of Sirt1 in TGF- $\beta 1$ profibrogenic activity. Our data showed that TGF- $\beta 1$ treatment for 24 hours remarkably decreased the Sirt1 level, which was accompanied by a significant upregulation in matrix accumulation and EMT. Furthermore, we showed that overexpression of Sirt1 also abolished TGF- $\beta 1$-induced upregulation of Col1, TIMP-1, and PAI-1 expression. These findings indicate that Sirt1 may functionally participate in the fibrogenesis induced by TGF- $\beta 1$ in HK-2 cells, and suggest a beneficial role for Sirt1 in protecting the kidney from fibrosis; this result supports previous studies that showed an antifibrotic effect for resveratrol. ${ }^{41-43}$

We also demonstrated that Sirt1 overexpression effectively attenuated apoptosis in TGF- $\beta 1$-treated HK-2 cells. TUNEL analysis, Hoechst 33258 staining, and FCM Annexin V/PI staining assay all exhibited the inhibition in the rhTGF- $\beta 1$-induced apoptosis rate in HK-2 cells overexpressing Sirt1 at 24 hours. Western blotting and real-time RT-PCR revealed that Sirt1 overexpression increased Bcl-2 protein and mRNA levels, and decreased Bax protein and mRNA levels. Several studies have reported a protective effect for Sirt1 on apoptosis in multiple organs and tissues, such as the liver, ${ }^{44}$ lung, ${ }^{45}$ thyroid,${ }^{46}$ pancreas, ${ }^{47}$ stomach, ${ }^{48}$ neurons, ${ }^{49}$ retina,${ }^{50}$ and kidney, against injury due to diverse causes. $\mathrm{H}_{2} \mathrm{O}_{2}$-induced apoptosis was significantly attenuated in Sirt1-overexpressing murine mesangial cells (MMCs), but enhanced in Sirt1-knockdown MMCs. ${ }^{51}$ Moreover, the downregulation of Sirt1 expression in diabetes promoted podocyte apoptosis. ${ }^{52}$ The UUO model of kidney injury induced markedly increased renal apoptosis and fibrosis in Sirt1+/- mice compared with wild-type controls, while pharmacologic Sirt1 activation substantially attenuated apoptosis and fibrosis in wild-type mice. ${ }^{17}$ These findings further support the proposal that Sirt1 may be a promising therapeutic target of a common pathway of renal apoptosis and fibrosis.

In this study, we observed a close association between increased CTGF expression or decreased Sirt1 expression and renal fibrogenesis. These data suggest the possibility of a relationship between Sirt1 and CTGF. We found that Sirt1 expression and activity were significantly decreased in the UUO obstructed mouse kidney. In contrast, Sirt1 expression and activity were not altered following CTGF siRNA plasmid treatment in obstructive kidneys for 7 days. rhTGF- $\beta 1$ ( $5 \mathrm{ng} / \mathrm{mL}$ ) treatment for 24 hours remarkably increased CTGF levels and decreased Sirt1 levels in HK-2 cells. Nevertheless, the decrease in Sirt1 induced by rhTGF- $\beta 1$ was not attenuated by CTGF siRNA. To further evaluate the relationship between Sirt1 and CTGF, we transfected HK-2 cells with a Sirt1 overexpression plasmid, and then investigated the effect of overexpressed Sirt1 on CTGF. Our results showed that overexpression of Sirt1 dramatically suppressed CTGF expression at the protein level in the presence of rhTGF- $\beta 1$. These in vitro findings support the notion that it is likely that Sirt1 attenuates renal fibrogenesis and apoptosis by altering CTGF expression.

Only a few studies have discussed the relationship between Sirt1 and CTGF. Mao et $\mathrm{al}^{53}$ reported that the expression of Sirt1 was significantly upregulated in tumor samples from hepatocarcinoma patients, and Sirt1 mRNA levels positively correlated with CTGF mRNA levels. The results of our study and Mao's study seem to lead to diametrically opposite conclusions. It has been demonstrated that Sirt1 is overexpressed in prostate, colon, breast, gastric, liver, and pancreatic tumors, ${ }^{54}$ while Sirt1 deficiency under various stress conditions, such as metabolic or oxidative stress or hypoxia, has been implicated in the pathophysiologies of agerelated diseases including diabetes, cardiovascular diseases, neurodegenerative disorders, and renal diseases. ${ }^{55}$ Taken together, it is reasonable to speculate that the discrepancy between the two conclusions is due to the presence of tumors or other disease. This hypothesis requires further study. 


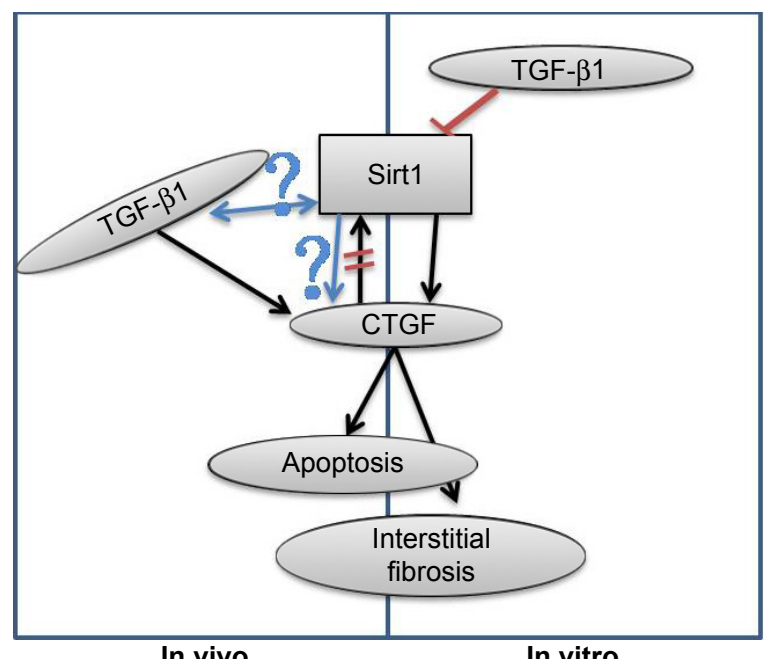

In vivo

In vitro

Figure II Schematic representation of the proposed model of the relationship between Sirtl and TGF- $\beta$ I/CTGF in tubulointersitial fibrosis.

Notes: In vitro, TGF- $\beta$ I decreases Sirtl and induces CTGF, further augmenting interstitial fibrosis and apoptosis. In vivo, kidney injury induced by UUO results in activation of TGF- $\beta$ I/CTGF and leads to the reduction of Sirtl. CTGF siRNA ameliorated tubular cell apoptosis and tubulointerstitial fibrosis independent of Sirtl. Understanding the interactions precisely between Sirtl and TGF- $\beta$ I/CTGF presents the next challenge.

Abbreviations: TGF- $\beta$ I, transforming growth factor- $\beta$ I; Sirt I, mammalian sirtuin I; CTGF, connective tissue growth factor; UUO, unilateral ureteral obstruction.

In summary, we detected increased TGF and CTGF, and decreased Sirt1 expression levels in obstructed mouse kidneys. CTGF plays a direct and substantial role in the development of interstitial fibrosis in the kidney. This study also provides evidence that treatment strategies involving the delivery of siRNA targeting potentially therapeutic transgenes may be efficacious. Our results suggest that a decrease in Sirt1 is associated with the upregulated expression of CTGF in renal fibrosis. Additional insight into the relationship between Sirt1 with TGF- $\beta 1 /$ CTGF in vivo will require with appropriate genetic, pharmacological, and physiological tools. Once this is achieved, it is expected that Sirt1 could become potential interesting targets for future therapies against fibrosis-related diseases (Figure 11).

\section{Acknowledgments}

The authors would like to acknowledge and thank Dr Michael E Greenberg for valuable contributions on providing free Sirt1 overexpressing plasmid. This work was supported by the National Natural Science Foundation of China (number 81200532) and the Natural Science Foundation of Hebei Province (number H2012206132).

\section{Disclosure}

The authors report no conflicts of interest in this work.

\section{References}

1. Nangaku M. Chronic hypoxia and tubulointerstitial injury: a final common pathway to end-stage renal failure. J Am Soc Nephrol. 2006;17: $17-25$.

2. Klahr S, Morrissey J. Obstructive nephropathy and renal fibrosis. $A m$ J Physiol Renal Physiol. 2002;283:F861-F875.

3. Camelo A, Dunmore R, Sleeman MA, Clarke DL. The epithelium inidiopathic pulmonary fibrosis: breaking the barrier. Front Pharmacol. 2013;7:173.

4. Luedde T, Kaplowitz N, Schwabe RF. Cell death and cell death responses in liver disease: mechanisms and clinical relevance. Gastroenterology. 2014;147:765-783.

5. Alberti C. Congenital ureteropelvic junction obstruction: physiopathology, decoupling of tout court pelvic dilatation-obstruction semantic connection, biomarkers to predict renal damage evolution. Eur Rev Med Pharmacol Sci. 2012;16:213-219.

6. Huang JS, Chuang LY, Guh JY, Huang YJ, Hsu MS. Antioxidants attenuate high glucose-induced hypertrophic growth in renal tubular epithelial cells. Am J Physiol Renal Physiol. 2007;293:F1072-F1082.

7. Gobe GC, Axelsen RA. Genesis of renal tubular atrophy in experimental hydronephrosis in the rat. Lab Invest. 1987;56:273-281.

8. Misseri R, Meldrum KK. Mediators of fibrosis and apoptosis in obstructive uropathies. Curr Urol Rep. 2005;6:140-145.

9. Jun JI, Lau LF. Taking aim at the extracellular matrix:CCN proteins as emerging therapeutic targets. Nat Rev Drug Discov. 2011;10: 945-963.

10. Rachfal AW, Brigstock DR. Structural and functional properties of CCN proteins. Vitam Horm. 2005;70:69-103.

11. Hishikawa K, Oemar BS, Nakaki T. Static pressure regulates connective tissue growth factor expression in human mesangial cells. J Biol Chem. 2001;276:16797-16803.

12. Yang HW, Chen XL, Liu ZL, Liu J, Bu LM. CTGFsiRNA ameliorates retinal cells apoptosis in streptozotocin-induced diabetic rats. Int J Ophthalmol. 2010;3:120-124.

13. Michan S, Sinclair D. Sirtuins in mammals: insights into their biological function. Biochem J. 2007;404:1-13.

14. Kim DH, Jung YJ, Lee JE, et al. SIRT1 activation by resveratrol ameliorates cisplatin-induced renal injury through deacetylation of p $53 . \mathrm{Am}$ J Physiol Renal Physiol. 2011;301:F427-F435.

15. Huang XZ, Wen D, Zhang M, et al. Sirt1 activation ameliorates renal fibrosis by inhibiting the TGF- $\beta /$ Smad3 pathway. J Cell Biochem. 2014;115: 996-1005.

16. Kume S, Haneda M, Kanasaki K, et al. SIRT1 inhibits transforming growth factor beta-induced apoptosis in glomerular mesangial cells via Smad7 deacetylation. J Biol Chem. 2007;282(1):151-158.

17. He W, Wang Y, Zhang MZ, et al. Sirt1 activation protects the mouse renal medulla from oxidative injury. J Clin Invest. 2010;120:1056-1068.

18. Chiarappa FE. The Effect of Exogenous Sryl and Sry3 on the Rat Kidney. Akron, OH: The University of Akron; 2010:9.

19. Schimizu H, Maruyama S, Yuzawa Y, et al. Anti-monocyte chemoattractant protein-1 gene therapy attenuated renal injury induced by proteinoverload proteinuria. J Am Soc Nephrol. 2002;14:1496-1505.

20. Brunet A, Sweeney LB, Sturgill JF, et al. Stress-dependent regulation of FOXO transcription factors by the SIRT1 deacetylase. Science. 2004;303: 2011-2015.

21. Livak KJ, Schmittgen TD. Analysis of relative gene expression data using real-time quantitative PCR and the 2- $\Delta \Delta$ CT method. Methods. 2001;25(4): 402-408.

22. Bitzer M, Sterzel RB, Böttinger EP. Transforming growth factor-beta in renal disease. Kidney Blood Press Res. 1998;21:1-12.

23. Liu Y. Cellular and molecular mechanisms of renal fibrosis. Nat Rev Nephrol. 2011;7(12):684-696.

24. Song Y, Zhan L, Yu M, et al. TRPV4 channel inhibits TGF- $\beta 1$-induced proliferation of hepatic stellate cells. PLoS One. 2014;9:e101179.

25. Estany S, Vicens-Zygmunt V, Llatjós R, et al. Lung fibrotic tenascin-C upregulation is associated with other extracellular matrix proteins and induced by TGFß1. BMC Pulm Med. 2014;14:120-142. 
26. Leight JL, Wozniak MA, Chen S, Lynch ML, Chen CS. Matrix rigidity regulates a switch between TGF-beta 1-induced apoptosis and epithelialmesenchymal transition. Mol Biol Cell. 2012;3:781-791.

27. Gomez EW, Chen QK, Gjorevski N, Nelson CM. Tissue geometry patterns epithelial-mesenchymal transition via intercellular mechanotransduction. J Cell Biochem. 2010;110:44-51.

28. Abreu JG, Ketpura NI, Reversade B, De Robertis EM. Connective-tissue growth factor (CTGF) modulates cell signalling by BMP and TGF-beta. Nat Cell Biol. 2002;4:599-604.

29. Leask A, Abraham DJ. TGF-beta signaling and the fibrotic response. FASEB J. 2004;18(7):816-827.

30. Chen X, Qi W, Pollock CA. CTGF and chronic kidney fibrosis. Front Biosci. 2009;1:132-141.

31. Border WA, Noble NA. Transforming growth factor beta in tissue fibrosis. N Engl J Med. 1994;331:1286-1292.

32. Ito Y, Aten J, Bende RJ, et al. Expression of connective tissue growth factor in human renal fibrosis. Kidney Int. 1998;53:853-861.

33. Yokoi H, Sugawara A, Mukoyama M, et al. Role of connective tissue growth factor in profibrotic action of transforming growth factor-beta a potential target for preventing renal fibrosis. Am J Kidney Dis. 2001; 38:S134-S138

34. Tanno M, Kuno A, Yano T, et al. Induction of manganese superoxide dismutase by nuclear translocation and activation of SIRT1 promotes cell survival in chronic heart failure. J Biol Chem. 2010;285:8375-8382.

35. Alcendor RR, Gao S, Zhai P, et al. Sirt1 regulates aging and resistance to oxidative stress in the heart. Circ Res. 2007;100:1512-1521.

36. Costa Cdos S, Hammes TO, Rohden F, et al. SIRT1 transcription is decreased in visceral adipose tissue of morbidly obese patients with severe hepatic steatosis. Obes Surg. 2010;20:633-639.

37. Kitada M, Takeda A, Nagai T, Ito H, Kanasaki K, Koya D. Dietary restriction ameliorates diabetic nephropathy through anti-inflammatory effects and regulation of the autophagy via restoration of Sirt1 in diabetic Wistar fatty (fa/fa) rats: a model of type 2 diabetes. Exp Diabetes Res. 2011; 2011:908185.

38. Liao YC, Wang YS, Guo YC, Lin WL, Chang MH, Juo SH. Let-7g improves multiple endothelial functions through targeting transforming growth factor-beta and SIRT-1 signaling. J Am Coll Cardiol. 2014;63: $1685-1694$.

39. Yao QP, Zhang P, Qi YX, et al. The role of SIRT6 in the differentiation of vascular smooth muscle cells in response to cyclic strain. Int J Biochem Cell Biol. 2014;49:98-104.

40. Minagawa S, Araya J, Numata T, et al. Accelerated epithelial cell senescence in IPF and the inhibitory role of SIRT6 in TGF- $\beta$-induced senescence of human bronchial epithelial cells. Am J Physiol Lung Cell Mol Physiol. 2011;300:L391-L401.

41. Aubin MC, Lajoie C, Clément R, Gosselin H, Calderone A, Perrault LP. Female rats fed a high-fat diet were associated with vascular dysfunction and cardiac fibrosis in the absence of overt obesity and hyperlipidemia: therapeutic potential of resveratrol. J Pharmacol Exp Ther. 2008;325:961-968.
42. Hashem MA, Jun KY, Lee E, Lim S, Choo HY, Kwon Y. A rapid and sensitive screening system for human type I collagen with the aim of discovering potent anti-aging or anti-fibrotic compounds. Mol Cells. 2008;26:625-630.

43. Inanaga $\mathrm{K}$, Ichiki $\mathrm{T}$, Matsuura $\mathrm{H}$, et al. Resveratrol attenuates angiotensin II-induced interleukin-6 expression and perivascular fibrosis. Hypertens Res. 2009;32:466-471.

44. Xu W, Lu Y, Yao J, et al. Novel role of Resveratrol: suppression of HMGB1 nucleocytoplasmic translocation by the upregulation of SIRT1 in sepsis-induced liver injury. Shock. 2014;42:440-447.

45. Hassan MK, Watari H, Salah-Eldin AE, et al. Histone deacetylase inhibitors sensitize lung cancer cells to hyperthermia: involvement of Ku70/SirT-1 in thermo-protection. PLoS One. 2014;9:e94213.

46. Kweon KH, Lee CR, Jung SJ, et al. Sirt1 induction confers resistance to etoposide-induced genotoxic apoptosis in thyroid cancers. Int J Oncol. 2014; 45:2065-2075.

47. Huang B, Cheng X, Wang D, et al. Adiponectin promotes pancreatic cancer progression by inhibiting apoptosis via the activation of AMPK/ Sirt1/PGC-1 $\alpha$ signaling. Oncotarget. 2014;5:4732-4745.

48. Hirai S, Endo S, Saito R, et al. Antitumor effects of a Sirtuin inhibitor, tenovin-6, against gastric cancer cells via death receptor 5 up-regulation. PLoS One. 2014;9:e102831.

49. Li J, Feng L, Xing Y, et al. Radioprotective and antioxidant effect of resveratrol in hippocampus by activating Sirt1. Int J Mol Sci. 2014;15: 5928-5939.

50. Bhattacharya S, Chaum E, Johnson DA, Johnson LR. Age-related susceptibility to apoptosis in human retinal pigment epithelial cells is triggered by disruption of $\mathrm{p} 53-\mathrm{Mdm} 2$ association. Invest Ophthalmol Vis Sci. 2012;53:8350-8366.

51. Kume S, Haneda M, Kanasaki K, et al. Silent information regulator 2 (SIRT1) attenuates oxidative stress-induced mesangial cell apoptosis via p53 deacetylation. Free Radic Biol Med. 2006;40:2175-2182.

52. Chuang PY, Dai Y, Liu R, et al. Alteration of forkhead box O (foxo4) acetylation mediates apoptosis of podocytes in diabetes mellitus. PLoS One. 2011;6(8):e23566.

53. Mao B, Hu F, Cheng J, et al. SIRT1 regulates YAP2-mediated cell proliferation and chemoresistance in hepatocellular carcinoma. Oncogene. 2014;33: $1468-1474$.

54. Shackelford RE, Mayhall K, Maxwell NM, Kandil E, Coppola D. Nicotinamide phosphoribosyl transferase in malignancy. Genes Cancer. 2013;4: 447-445.

55. Kitada M, Kume S, Takeda-Watanabe A, Kanasaki K, Koya D. Sirtuins and renal diseases: relationship with aging and diabetic nephropathy. Clin Sci (Lond). 2013;124:153-164.
Drug Design, Development and Therapy

\section{Publish your work in this journal}

Drug Design, Development and Therapy is an international, peerreviewed open-access journal that spans the spectrum of drug design and development through to clinical applications. Clinical outcomes, patient safety, and programs for the development and effective, safe, and sustained use of medicines are a feature of the journal, which

\section{Dovepress}

has also been accepted for indexing on PubMed Central. The manuscript management system is completely online and includes a very quick and fair peer-review system, which is all easy to use. Visit http://www.dovepress.com/testimonials.php to read real quotes from published authors. 